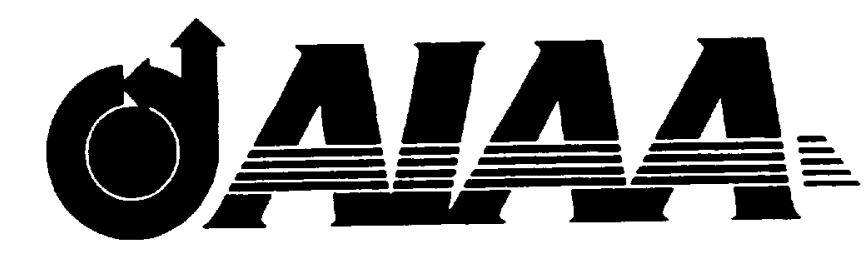

AIAA-2003-0752

\title{
X-29 High Alpha Test in the National Transonic Facility (Invited)
}

Pamela J. Underwood, ViGYAN, Inc.

Hampton, VA 23666

Lewis R. Owens, Richard A. Wahls, and Susan Williams NASA Langley Research Center

Hampton, VA 23681

\section{1st AIAA Aerospace Sciences Meeting \& Exhibit 6 - 9 January 2003 \\ Reno, Nevada}





\title{
X-29 High Alpha Test in the National Transonic Facility
}

\author{
Pamela J. Under wood ${ }^{*}$ \\ ViGYAN, Inc., Hamptcn, VA 23666
}

Lewis R. Owens', Richard A. Wahls', Susan Williams ${ }^{\S}$

NASA Langley Research Center. Hampton, VA 23681

\begin{abstract}
$\underline{\text { Abstract }}$
This paper describes the X-29A research program at the National Transonic Facility. This wind tunnel test leveraged the X-29A high alpha flight test program by enabling ground-to-flight correlation studies with an emphasis on Reynolds number effects. The background and objectives of this test program, as well as the comparison of high Reynolds number wind tunnel data to X-29A flight test data are presented. The effects of Reynolds number on the forebody pressures at high angles of attack are also presented. The purpose of this paper is to document this test and serve as a reference for future ground-toflight correlation studies, and high angle-of-attack investigations. Good ground-to-flight correlations were observed for angles of attack up to $50^{\circ}$, and Reynolds number effects were also observed.
\end{abstract}

\section{Nomenclature}

\begin{tabular}{|c|c|}
\hline $\mathrm{c}$ & mean aerodynamic chord, in \\
\hline$\overline{C_{N}}$ & normal force coefficient \\
\hline$C_{P}$ & pressure coefficient \\
\hline $\mathrm{C}_{\mathrm{Y}}$ & side force coefficient \\
\hline DARPA & $\begin{array}{l}\text { Defense Advanced Research } \\
\text { Projects Agency }\end{array}$ \\
\hline ESP & electronically scanned pressure \\
\hline $\mathbf{F}$ & degrees Fahrenheit \\
\hline 1 & fuselage or body length, in \\
\hline $\mathrm{M}$ & Mach number \\
\hline NTF & National Transonic Facility \\
\hline$P_{t}$ & total pressure, psi \\
\hline $\mathbf{R}_{\mathrm{C}}$ & $\begin{array}{l}\text { Reynolds number based on mean } \\
\text { aerodynamic chord }\end{array}$ \\
\hline $\operatorname{Re}_{\mathrm{D}}$ & $\begin{array}{l}\text { Reynolds number based on } \\
\text { forebody diameter }\end{array}$ \\
\hline $\mathrm{S}$ & Wing reference area, in ${ }^{2}$ \\
\hline $\mathrm{T}_{1}$ & total temperature, ${ }^{\circ} \mathrm{F}$ \\
\hline USAF & United States Air Force \\
\hline $\mathrm{x}$ & axial distance from nose apex, in \\
\hline$\alpha$ & angle of attack, deg \\
\hline$\theta$ & circumferential angle, deg \\
\hline
\end{tabular}

\footnotetext{
"Research Engineer, Member AIAA

1 Aerospace Engineer, Flow Physics and Control Branch, Senior Member ALAA

- Asst. Head. Configuration Aerodynamics Branch, Associate Fellow AIAA

\& Aerospace Engineer

This material is declared work of the U.S. Govermment and is not subject to copyright protection in the United States.
}

\section{Introduction}

$A$ joint research program to investigate the high angle-of-attack performance potential of the X-29A corward swept wing fighter commenced in the $1980^{\circ} \mathrm{s}$. Primary partners in this joint program were VASA, Grumman Aerospace, the United States Air Force (USAF), and the Defense Advanced Research Projects Agency (DARPA). During the high angleof-attack flight test, data were obtained to support Lerodynamics, flow visualization, control systems, handling qualities, and maneuverability research. A more extensive description of this flight program may be found in reference 1. The National Transonic Facility (NTF) X-29 High Alpha test was established to augment this flight research program by enabling ground-to-flight correlation studies with emphasis on Reynolds number effects. Portions of the data from this wind tunnel test have been previously published in related articles. ${ }^{2.3}$ The purpose of this paper is to further document this test and serve as a reference for future ground-to-flight correlation studies, and high angle-of-attack investigations.

\footnotetext{
Aircraft Description

The X-29A is a single place research airplane with a $29.27^{\circ}$ forward leading edge sweep wing, close coupled variable incidence canards, and full span dual hinged flaperons. ${ }^{4}$ The Grumman Aerospace designed X-29A is shown in figure 1. The forward swept wing is an aeroelastically tailored composite structure with a supercritical airfoil and a fixed leading edge. A 75-inch long nose boom. and 24inch long nose strakes are positioned at the nose apex. Side and bottom views of the nose apex are shown in figure 2.
} 


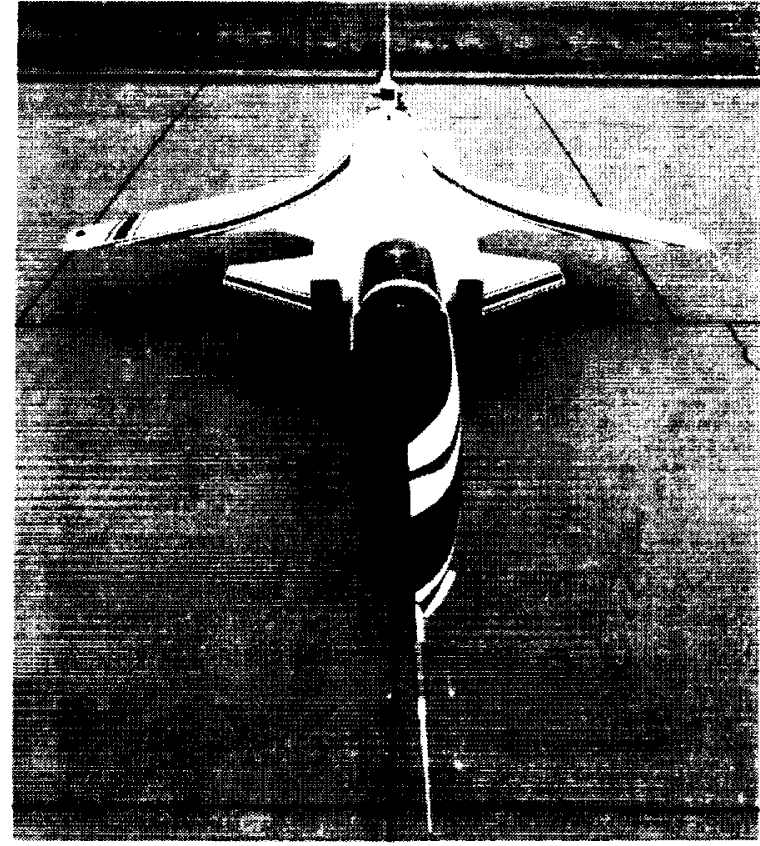

Figure 1: Grumman Aerospace X-29A
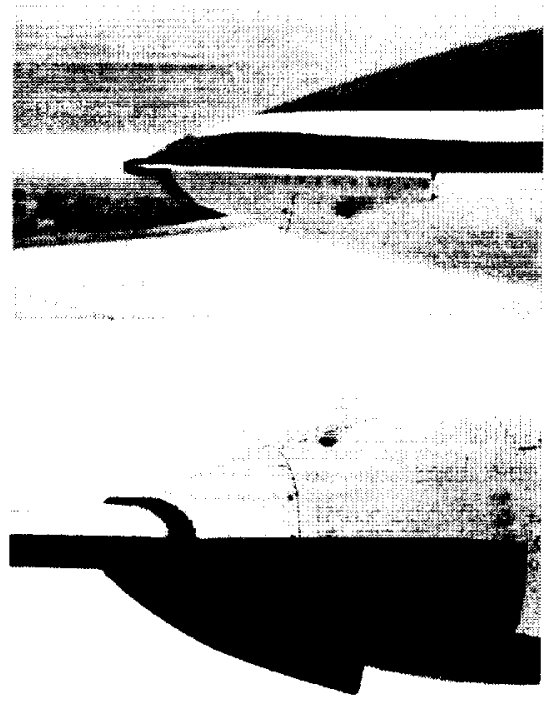

Figure 2: Side and Bottom View of Nose Apex

The nose boom tapered from a 0.88 -inch diameter at the tip to a 3.5-inch diameter at the nose apex, and the nose strakes were 1.5 inches wide at the nose apex and 2.5 inches wide at the downstream end. As shown in figure 3 the research airplane was instrumented with four circumferential rows of static pressure orifices.

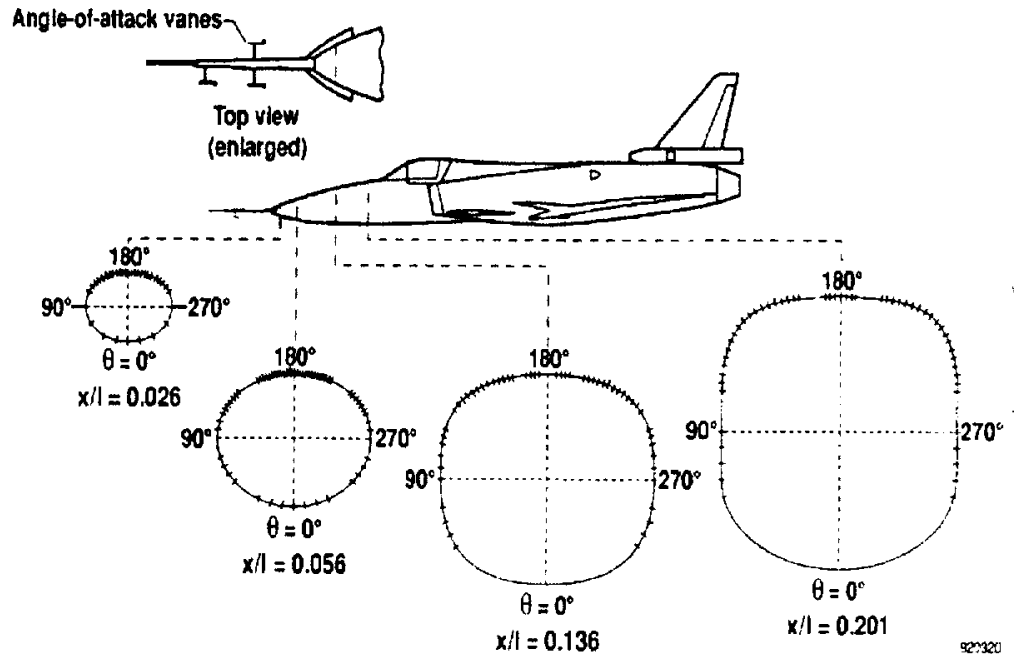

Figure 3: X-29A Research Aircraft Forebody Pressure Locations

The distribution of these static pressure rows is also shown in figure 3 , where $0^{\circ}$ is the windward side of the fuselage, $90^{\circ}$ is the starboard side, and $180^{\circ}$ is the leeward side. In addition to these static pressure orifices on the forebody, the research airplane was also instrumented with three angle of attack vanes and one angle of sideslip vane on the nose boom.

\section{Facility Description}

The NTF is a unique transonic wind tunnel designed to conduct full-scale flight Reynolds number testing through the use of high pressures and cryogenic temperatures. This is a fan driven, closed circuit wind tunnel with an 8.2-foot by 8.2-foot and 25-foot long test section with a slotted ceiling and floor. A planform view of the tunnel is provided in figure 4.

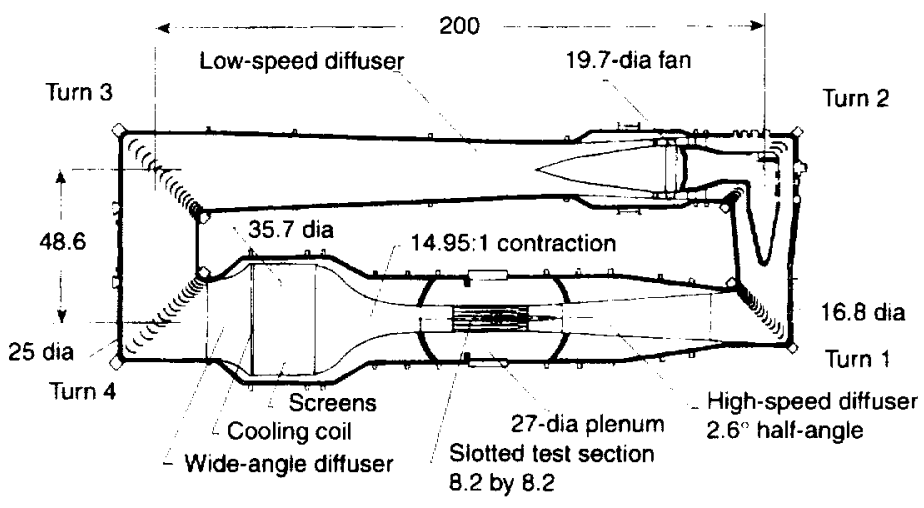

Figure 4: Planform View of the NTF

The tunnel operates using either dry air or gaseous nitrogen as the test medium. During air operations the tunnel pressure is used to control Reynolds number, while in the cryogenic nitrogen mode the tunnel temperature and pressure are used to control Reynolds number. The NTF affords a test 
environment in which the Mach number and chord Reynolds number are identical for the scale model in the test section and the full-scale aircraft in flight. The NTF is capable of an absolute pressure range from 15 psia to 125 psia, a temperature range from $-320^{\circ} \mathrm{F}$ to $150^{\circ} \mathrm{F}$, a Mach number range from 0.2 to 1.2 , and a maximum Reynolds number of $146 \times 10^{6}$ per $\mathrm{ft}$ at Mach 1. Typical tests use a temperature range from $-250^{\circ} \mathrm{F}$ to $120^{\circ} \mathrm{F}$. A more extensive facility description can be found in reference 5 .

\section{NTF X-29 Test Program}

The primary test objectives were to compare the NTF high Reynolds number forebody pressure data to the data obtained during the $\mathrm{X}-29 \mathrm{~A}$ high alpha flight test, and to assess the Reynolds number effects on the forebody flow at high angles of attack. The effect of fixing transition on the forebody was also studied during this test program.

\section{$1 / 16^{\text {th }}$ Scale X-29 Model}

The NTF X-29 model is a $1 / 16^{\text {th }}$ scale representation of the research airplane. All of the components of the $X-29 A$ research airplane were accurately scaled for the NTF model except for the thickness of the nose strakes. At $1 / 16^{\text {th }}$ scale the model nose strakes should have been 0.0075 inches thick, but were actually 0.03 inches thick due to NTF model strength requirements. Pertinent model geometry is given in figure 5.
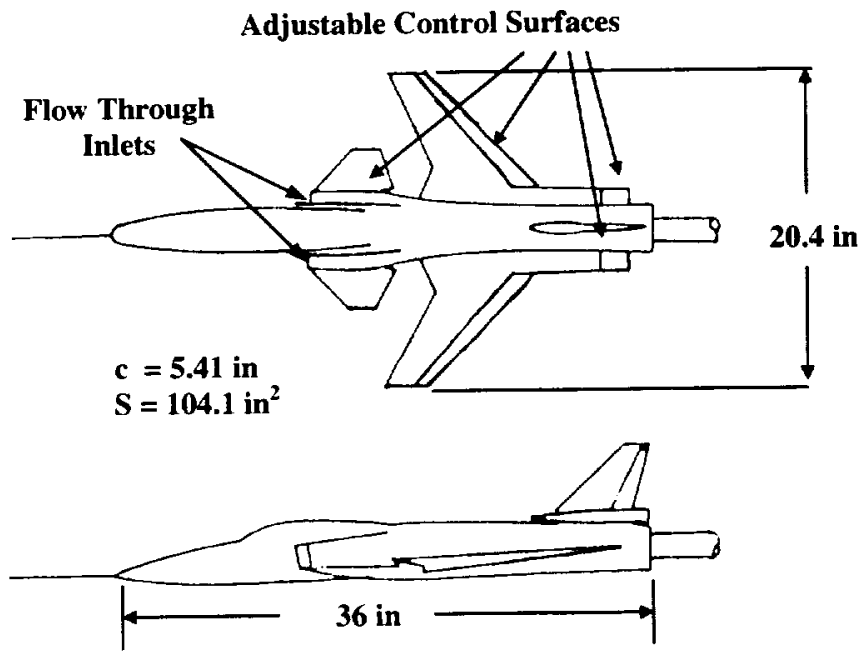

Figure 5: $1 / 16^{\text {th }}$ Scale X-29 Model Geometry
The $1 / 16^{\text {th }}$ scale NTF model featured flow through : nlets positioned on either side of the forebody just orward of the canards that combined to form a single xhaust at the back of the model. A flow shield was ncluded to isolate the balance from the interior duct low in this model.

The contour tolerance of the wing, canard, and vertical tail was \pm 0.002 inches. The fuselage forebody tolerance was \pm 0.004 inches, while the remaining fuselage tolerance was approximately \pm 0.004 inches to \pm 0.006 inches. The model was built of $18 \%$ nickel maraging steel (C type) with a surface finish of approximately 10 microinches (RMS). The model was composed of separable components to allow testing of multiple configurations. The flaperons, aft body strakes, rudder, and canards were all designed to be set at discrete angles. The $1 / 16^{\text {th }}$ scale NTF X-29 model is shown in figure 6 with all its control surface components. During this NTF test only the canard angle was varied. The model canard was designed to accommodate five discrete angle positions $\left(-20^{\circ}\right.$, $-25^{\circ},-30^{\circ},-35^{\circ},-60^{\circ}$ ), and was set to match the flight test conditions as closely as possible.

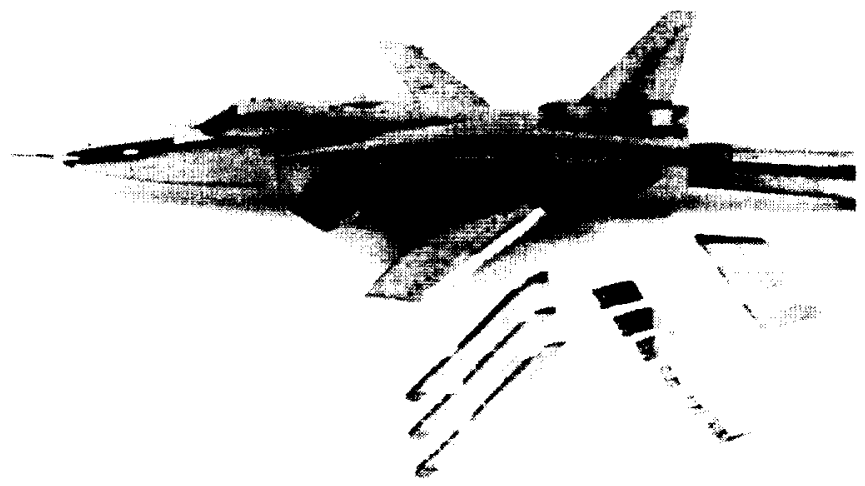

Figure 6: NTF X-29 Model with Control Surfaces

A unique high alpha sting was used with the X-29 model. This sting was designed to accommodate an angle of attack range from $-7^{\circ}$ to $74^{\circ}$ using three primary knuckle positions. A sketch of this high alpha sting showing the three possible knuckle positions is given in Figure 7. As seen in this sketch, only the second knuckle position keeps the model center of rotation aligned with the tunnel centerline, and positions \#1 and \#3 would present the model positions most susceptible for wall interference. Figure 8 shows the $1 / 16^{\text {th }}$ scale X-29 model mounted on the high alpha sting in the NTF test section. 


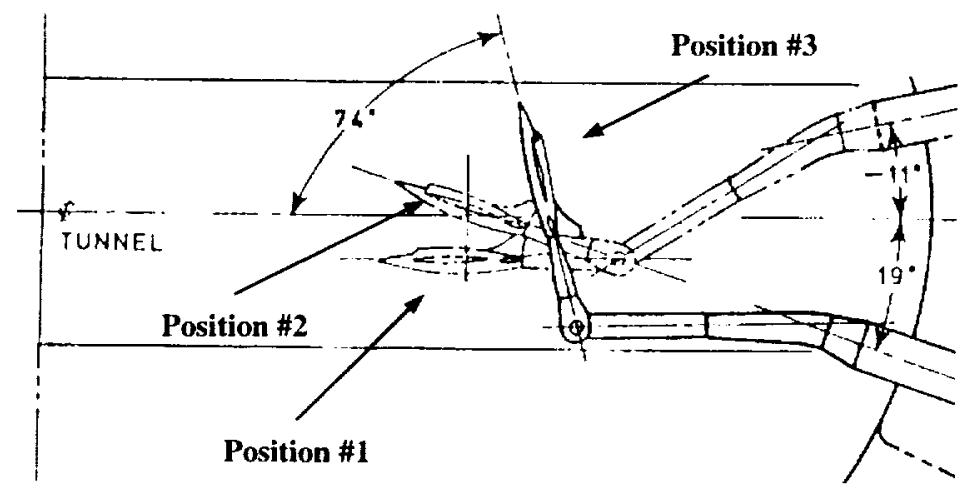

Figure 7: General Arrangement of NTF High Alpha Sting Depicting Three Knuckle Positions (Not to Scale)

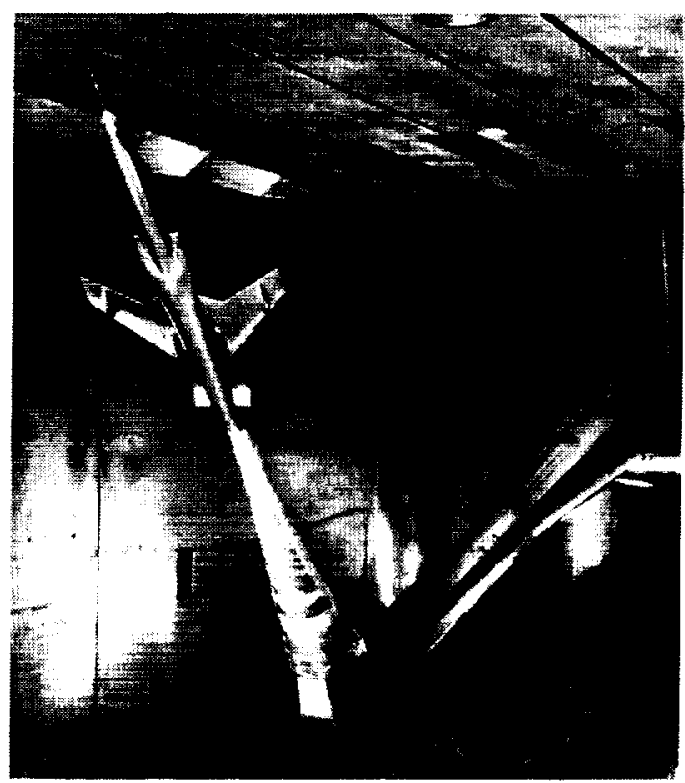

Figure 8: X-29 Model Mounted in NTF Test Section (Knuckle Position \#3)

Instrumentation and Measurement Corrections The NTF model was instrumented with one circumferential row of static pressure orifices on the forebody at station $x / 1=0.136$. This forebody location was chosen to correspond with one of the X-29A research airplane static pressure row locations (see figure 3 ). The circumferential distribution of the model static pressure orifices was also positioned to match the research airplane as closely as possible. Table 1 gives the circumferential pressure orifice locations for both the X-29 research airplane and the $X-29 \mathrm{NTF}$ model at $x / l=0.136$. Again, $0^{\circ}$ is the windward side of the fuselage, $90^{\circ}$ is the starboard side, and $180^{\circ}$ is the leeward side.

The NTF model forebody pressure data were obtained through the use of one internal 48 port electronically scanned pressure (ESP) module with a full-scale pressure range of \pm 15 psid. The quoted (worst case) accuracy of the ESP module was approximately 0.20 percent of full scale or \pm 0.030 psi $\left(C_{P}\right.$ variation \pm 0.06 at the lowest dynamic pressure condition). For reference, the X-29A high alpha flight test forebody pressure data were obtained using \pm 1.5 psi differential pressure transducers with an estimated accuracy of approximately $\pm 0.007 \mathrm{psi}^{4}{ }^{4}$ The model aerodynamic force and moment data were obtained with a six component unheated strain gage balance. The balance maximum load capacity and quoted accuracies are given in Table 2 . The axial force and moment data acquired were inconsistent, and deemed corrupt. These data show signs of interference on the balance most likely due to the tightly packed instrumentation within the model. Normal and side force data were less sensitive to this adverse effect, and are presented herein. The main objective was to compare forebody pressures with available flight data.

Table 1: Circumferential Static Pressure Locations, $\mathrm{x} / \mathrm{l}=\mathbf{0 . 1 3 6}$

\begin{tabular}{|c|c|}
\hline $\begin{array}{c}\text { NTF } \\
\theta(\mathrm{deg})\end{array}$ & $\begin{array}{c}\text { Flight } \\
\theta(\mathrm{deg})\end{array}$ \\
\hline 24.2 & $\mathrm{n} / \mathbf{a}$ \\
\hline 47.6 & $\mathrm{n} / \mathrm{a}$ \\
\hline 59.6 & 60.0 \\
\hline $\mathrm{n} / \mathrm{a}$ & 66.0 \\
\hline 72.0 & 72.0 \\
\hline 77.9 & 78.0 \\
\hline 83.9 & $\mathrm{n} / \mathrm{a}$ \\
\hline 89.8 & 90.0 \\
\hline 95.0 & 95.0 \\
\hline 99.9 & 100.0 \\
\hline 103.7 & 105.0 \\
\hline 107.7 & 108.0 \\
\hline 114.1 & 111.1 \\
\hline 119.9 & 120.0 \\
\hline 125.9 & 126.0 \\
\hline $\mathrm{n} / \mathrm{a}$ & 129.0 \\
\hline 131.9 & 132.0 \\
\hline $\mathrm{n} / \mathrm{a}$ & 135.0 \\
\hline 138.0 & 138.0 \\
\hline $\mathrm{n} / \mathrm{a}$ & 141.0 \\
\hline 143.9 & 144.0 \\
\hline $\mathrm{n} / \mathrm{a}$ & 147.0 \\
\hline 150.0 & 150.0 \\
\hline $\mathrm{n} / \mathrm{a}$ & 153.0 \\
\hline 155.9 & 156.0 \\
\hline 162.1 & 165.0 \\
\hline 167.9 & 168.0 \\
\hline $\mathrm{n} / \mathrm{a}$ & 171.0 \\
\hline 174.0 & 174.0 \\
\hline 180.0 & $\mathrm{n} / \mathrm{a}$ \\
\hline & \\
\hline
\end{tabular}

\begin{tabular}{|c|c|}
\hline $\begin{array}{c}\text { NTF } \\
\theta(\text { deg })\end{array}$ & $\begin{array}{c}\text { Flight } \\
\theta(\text { deg })\end{array}$ \\
\hline 185.9 & 186.0 \\
\hline $\mathrm{n} / \mathrm{a}$ & 189.0 \\
\hline 191.9 & 192.0 \\
\hline 197.7 & 195.0 \\
\hline 203.6 & 204.0 \\
\hline $\mathrm{n} / \mathrm{a}$ & 207.0 \\
\hline 209.8 & 210.0 \\
\hline $\mathrm{n} / \mathrm{a}$ & 213.0 \\
\hline 215.5 & 216.0 \\
\hline $\mathrm{n} / \mathrm{a}$ & 219.0 \\
\hline 221.4 & 222.0 \\
\hline $\mathrm{n} / \mathrm{a}$ & 225.0 \\
\hline 227.3 & 228.0 \\
\hline $\mathrm{n} / \mathrm{a}$ & 231.0 \\
\hline 234.7 & 234.0 \\
\hline $\mathrm{n} / \mathrm{a}$ & 237.0 \\
\hline 240.5 & 240.0 \\
\hline 246.2 & 249.0 \\
\hline 252.3 & 252.0 \\
\hline $\mathrm{n} / \mathrm{a}$ & 255.0 \\
\hline 260.3 & 260.0 \\
\hline 265.2 & 265.0 \\
\hline 270.0 & 270.0 \\
\hline 276.0 & 276.0 \\
\hline 288.0 & 288.0 \\
\hline $\mathrm{n} / \mathrm{a}$ & 294.5 \\
\hline 299.5 & 300.0 \\
\hline 336.1 & $\mathrm{n} / \mathrm{a}$ \\
\hline 360.0 & $\mathrm{n} / \mathrm{a}$ \\
\hline & \\
\hline
\end{tabular}


Table 2: NTF Balance Load Capacity

\begin{tabular}{|c|c|c|}
\hline Component & $\begin{array}{c}\text { Maximum } \\
\text { Load }\end{array}$ & $\begin{array}{c}\text { Full-Scale } \\
\text { Accuracy }\end{array}$ \\
\hline Normal Force & $\pm 2500 \mathrm{lb}$ & $0.10 \%$ \\
\hline Axial Force & $\pm 350 \mathrm{lb}$ & $0.26 \%$ \\
\hline Pitching Moment & $\pm 5000 \mathrm{in}-\mathrm{lb}$ & $0.11 \%$ \\
\hline Rolling Moment & $\pm 2500 \mathrm{in}-\mathrm{lb}$ & $0.40 \%$ \\
\hline Yawing Moment & $\pm 4000 \mathrm{in}-\mathrm{lb}$ & $0.18 \%$ \\
\hline Side Force & $\pm 1000 \mathrm{lb}$ & $0.35 \%$ \\
\hline
\end{tabular}

Space limitations inside the $1 / 16^{\text {th }}$ scale NTF model due to the flow shield around the balance, and the pressure instrumentation prohibited the use of an on board accelerometer to measure model angle-ofattack. These angles were measured using an arcsector mounted accelerometer package corrected for sting bending using the balance loads and support sting deflection sensitivities. These angle of attack measurements had an estimated accuracy of $\pm 0.1^{\circ}$. Further information on the tunnel instrumentation, data recording, and the data reduction algorithms is provided in reference 6 . The data herein were not corrected for wall interference, support tare and interference, and tunnel upflow.

\section{Test Conditions}

The NTF test program was designed to match Mach number, chord Reynolds number, and angle of attack with existing X-29A high alpha flight-test data. The test had a Mach number range from 0.22 to 0.25 at Reynolds numbers based on mean aerodynamic chord ranging from 0.7 to 6.8 million, and an angleof-attack range from 28 to 68 degrees. A limited set of data were acquired at $0.6 \mathrm{Mach}$ number, Reynolds numbers ranging from 1.6 to 8.3 million, and an angle of attack range from 28 to 42 degrees. The low Reynolds number testing ( $R_{C} \leq 3.3$ million) in air was conducted at total pressures ranging from approximately 16 to $75 \mathrm{psia}$, and total temperatures ranging from 75 to $100^{\circ} \mathrm{F}$. The high Reynolds number testing ( $R_{C} \geq 5$ million) in gaseous nitrogen had total pressures ranging from approximately 30 to $85 \mathrm{psia}$, with total temperatures ranging from -55 to $-200^{\circ} \mathrm{F}$. Overall the dynamic pressure ranged from approximately 70 to $800 \mathrm{psf}$.

\section{Results and Discussion}

\section{Tunnel to Flight Pressure Data Comparison}

A comparison of the forebody pressure distributions obtained from the NTF and flight is given in figures 9 through 11. These data are plotted as the coefficient of pressure $\left(C_{P}\right)$ versus radial forebody location $(\theta)$ in degrees. Once again $0^{\circ}$ represents the windward side of the fuselage, $90^{\circ}$ is the starboard side, and $180^{\circ}$ is the leeward side. All the data in hese figures were obtained without fixing transition in the $1 / 16^{\text {th }}$ scale NTF model. Figures $9 a$ and $9 b$ ure for test conditions of 0.25 Mach number (M). Reynolds number based on mean aerodynamic chord $\mathrm{R}_{\mathrm{C}}$ ) of approximately 6.6 million, and angles of Ittack $(\alpha)$ of approximately 30 and 35 degrees espectively. Figures $9 \mathrm{c}$ and $9 \mathbf{d}$ are for test onditions of $M \approx 0.22, R_{C} \approx 5.6$ million, and $\alpha \approx 40^{\circ}$ and $15^{\circ}$, respectively.

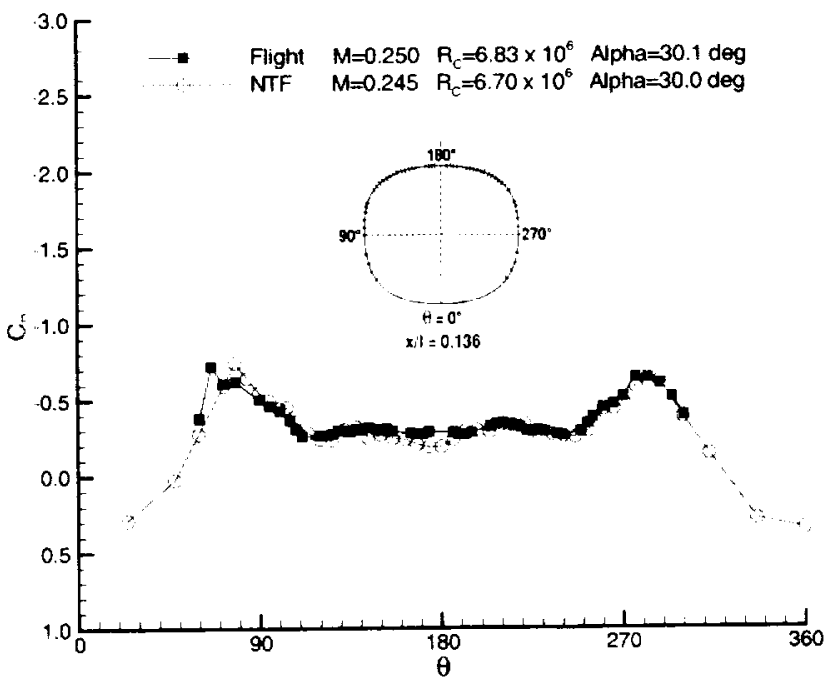

9a) $\alpha \approx 30^{\circ}$

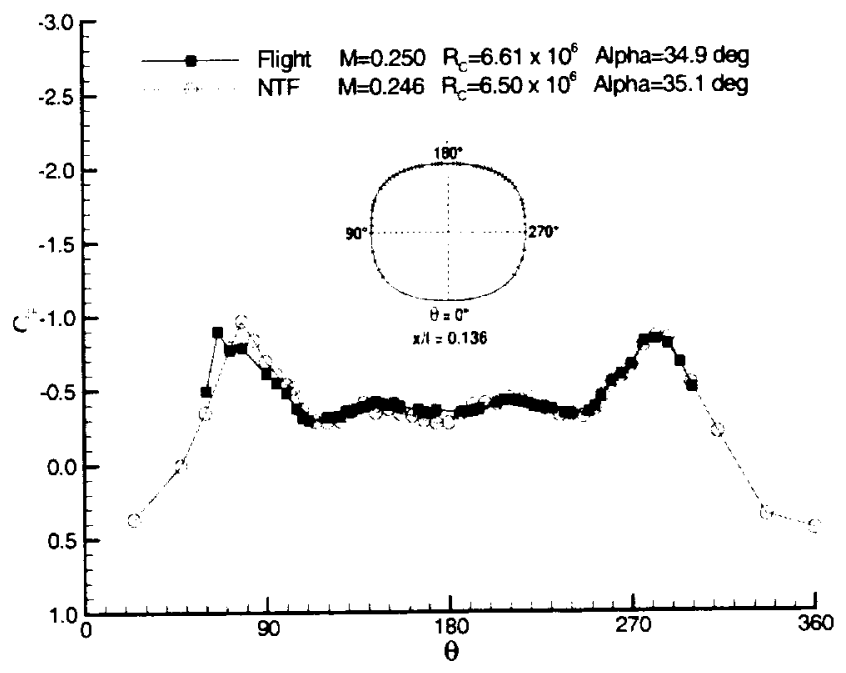

9b) $\alpha \approx 35^{\circ}$

Figure 9: NTF to Flight Forebody Pressure Distributions for $30^{\circ}<\alpha<45^{\circ}$ at $\mathrm{x} /=0.136$ 


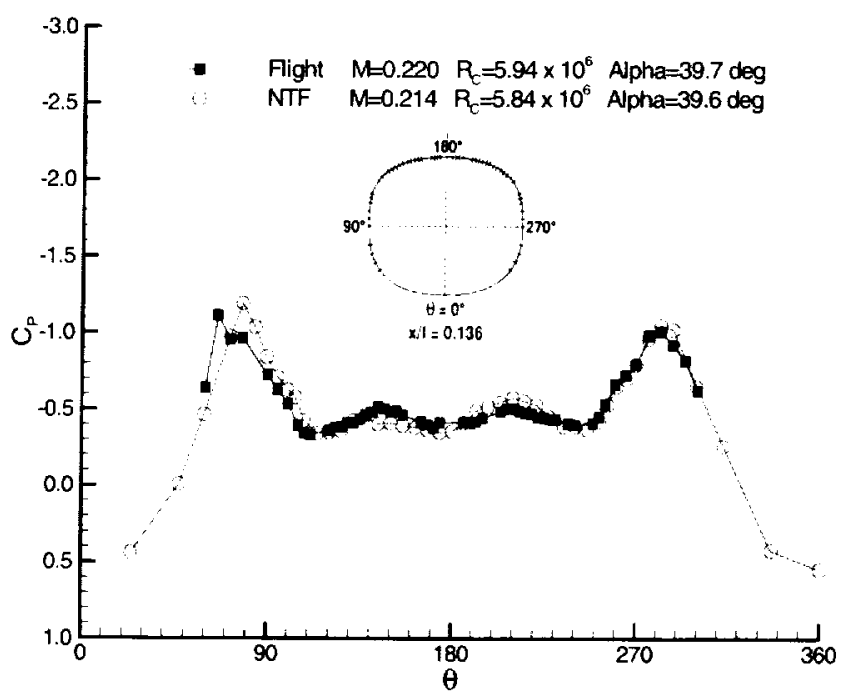

9c) $\alpha=40^{\circ}$

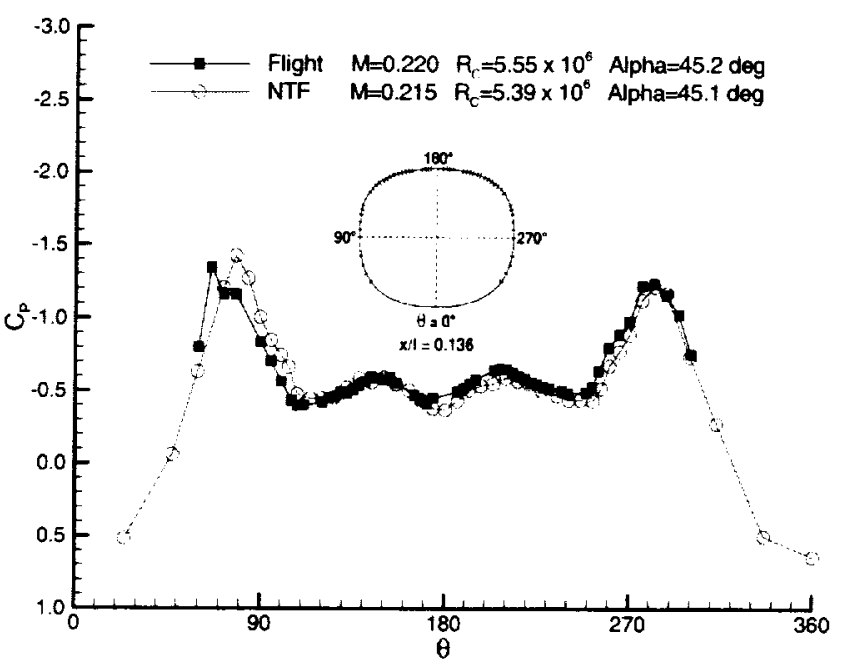

9d) $\alpha \approx \mathbf{4 5}^{\circ}$

Figure 9: Concluded

The primary suction peaks at $\theta \approx 70^{\circ}$ and $290^{\circ}$ indicate the local acceleration of the attached flow around this highly curved region of the forebody surface. After reaching the maximum forebody width, the flow begins to decelerate as it approaches the leeward side of the forebody. This deceleration continues until the flow separates at $\theta \approx 110^{\circ}$ and $250^{\circ}$. Finally, the effects of the vortices due to the forebody are noted by the secondary suction peaks at $\theta \approx 150^{\circ}$ and $210^{\circ}$. This type of pressure distribution is typical of that seen in previous forebody studies. ${ }^{7.10}$

An approximate $10^{\circ}$ off set exists between the NTF and the flight data on the starboard suction peak at

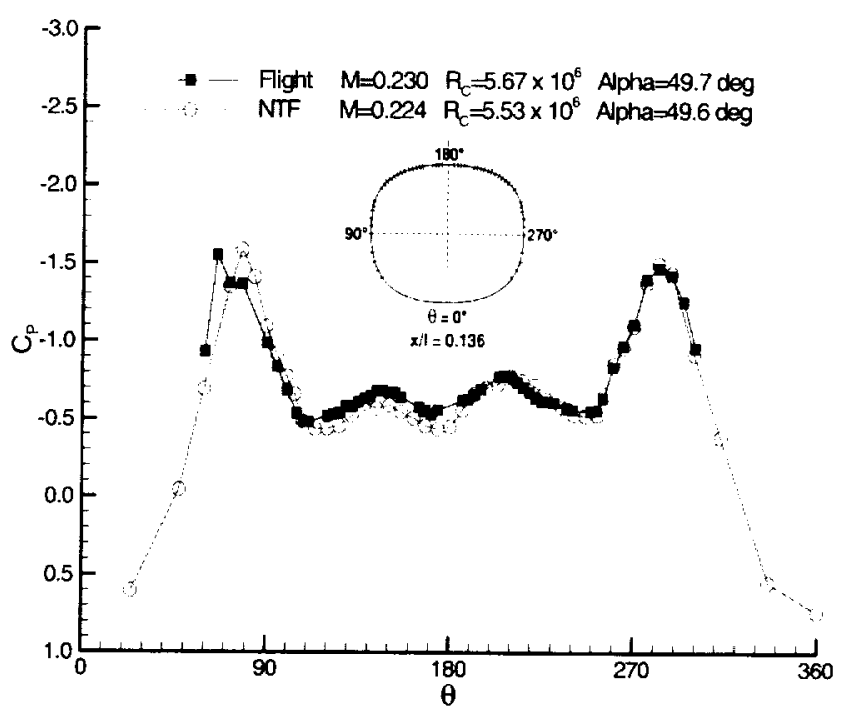

10a) $\alpha \approx 50^{\circ}$

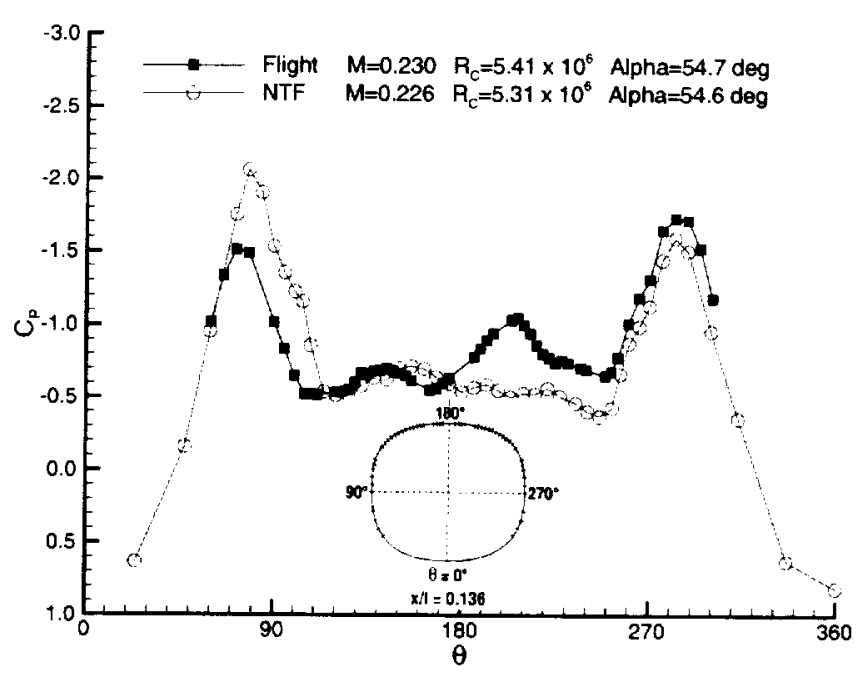

10b) $\alpha \approx 55^{\circ}$

Figure 10: NTF to Flight Forebody Pressure Distributions $50^{\circ}<\alpha<66^{\circ}$

$\theta \approx 70^{\circ}$. Since this off set remains fairly constant and exists in all of the forebody pressure data examined, it is most likely attributed to a slight geometric difference in the forebody cross-sectional geometry between the $1 / 16^{\text {th }}$ scale NTF model and the X-29A research airplane. As expected, all the pressure distributions remain fairly symmetric in this alpha range $\left(30^{\circ}<\alpha<45^{\circ}\right)$, and generally increase with angle of attack. Overall there is a good correlation between the NTF and flight forebody pressure distributions for angles of attack from 30 to 45 degrees.

Figures 10a through 10d have test conditions of $M \approx 0.23, R_{C} \approx 5.4$ million, and $\alpha \approx 50^{\circ}, 55^{\circ}, 59^{\circ}$, and $66^{\circ}$, respectively. There is still reasonable agreement 


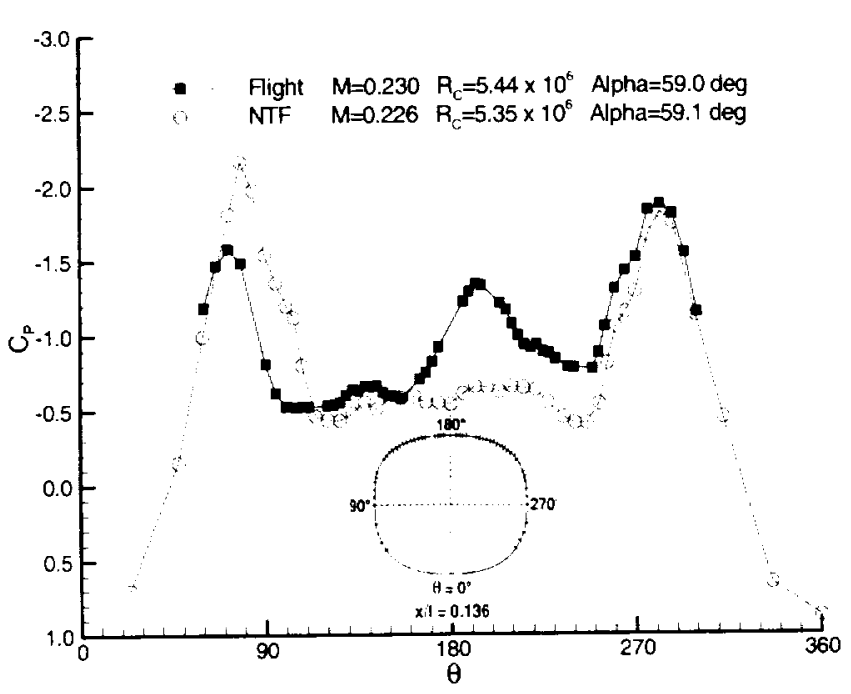

10c) $\alpha \approx 59^{\circ}$

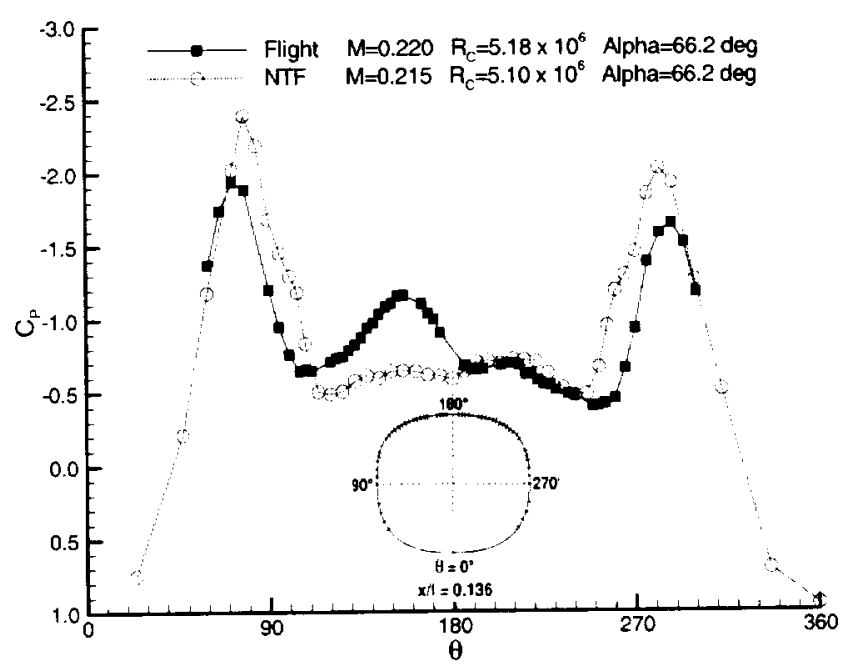

10d) $\alpha \approx 66^{\circ}$

\section{Figure 10: Concluded}

between the NTF data and the flight data at $\alpha \approx 50^{\circ}$, but for angles of attack above $50^{\circ}$ there is an appreciable difference between the two pressure distributions. At $\alpha \approx 55^{\circ}$ a distinct asymmetry develops between the forebody vortices in the flight data as indicated by the asymmetric secondary suction peaks. The starboard vortex at $\theta \approx 140^{\circ}$ lifts away from the surface while the port vortex at $\theta \approx 210^{\circ}$ shifts closer to the forebody causing a higher secondary suction peak under the vortex core. The proximity of the port vortex to the forebody also influences the primary suction peak at $\theta \approx 290^{\circ}$, and ultimately results in a nose left yawing moment for the research airplane. The pressure distribution for the NTF model is more symmetric than the flight data at this same angle of attack with only a slight nose tight yawing moment indication. The secondary : uction peak under the port forebody vortex for the NTF data is less pronounced here than it has been at the lower angles of attack.

At $\alpha=59^{\circ}$ the asymmetry between the forebody ortices in the flight pressure distribution is more pronounced, and again a pressure distribution issociated with the nose left tending yawing moment is observed. The NTF data at $\alpha \approx 59^{\circ}$ again is a more ymmetric than that of the flight data with only a light tendency toward a nose right yawing moment. The flight pressure distribution for $\alpha \approx 66^{\circ}$ indicate a hange in asymmetry resulting in a nose right yawing moment for the research airplane. which is typical for ery sensitive high Reynolds number forebody apex low fields. ${ }^{2,8.11}$ The NTF data at $\alpha \approx 66^{\circ}$ maintain haracteristics similar to $\alpha \approx 59^{\circ}$, and unlike the flight lata did not experience a change in yawing moment lirection.

Overall these differences in the pressure distributions setween the NTF and flight are most likely caused by the differences in both the boundary layer states, and the geometric modeling of the forebody apex, nose boom. and nose strakes. The differences in the boundary layers between the research airplane and the $1 / 16^{\text {th }}$ scale NTF model may be attributed to differences in the surface roughness between the two test articles. The NTF model had a very smooth surface finish (approximately 10 microinches), while the research airplane had longitudinal gaps and steps in the forebody due to instrumentation access panels that were located forward of the $x /=0.136$ pressure row. Other external equipment on the research airplane that could have affected the forebody flow especially at the higher angles of attack include an antenna, as well as the three angle of attack and one angle of sideslip vanes mounted on the nose boom. None of these access panels or other equipment was modeled on the $1 / 16^{\text {th }}$ scale NTF test article. When it is important to match high angle-of-attack flight conditions for this type of forebody flow field, then it is necessary to consider even the smallest geometric differences that may cause an asymmetry in the flow.

A source of error that may also contribute to the discrepancies observed between the NTF and flight data for $\alpha \geq 50^{\circ}$ would be the wall interference associated with using knuckle position \#3 on the high alpha sting. For this test, knuckle position \#3 placed the model in the closest proximity to the walls and makes the pressure distributions more susceptible to wall interference. 


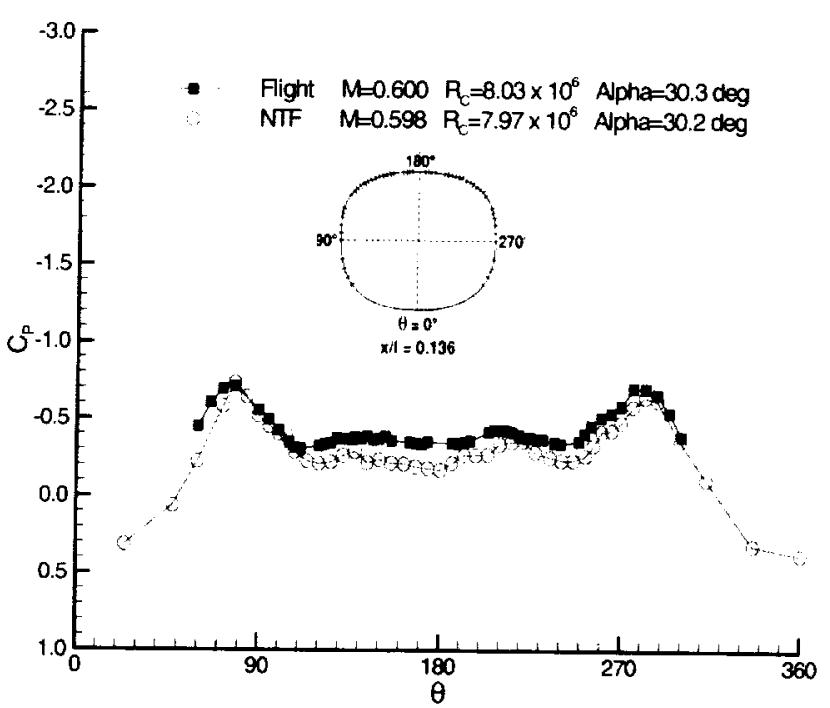

11a) $\alpha \approx 30^{\circ}$

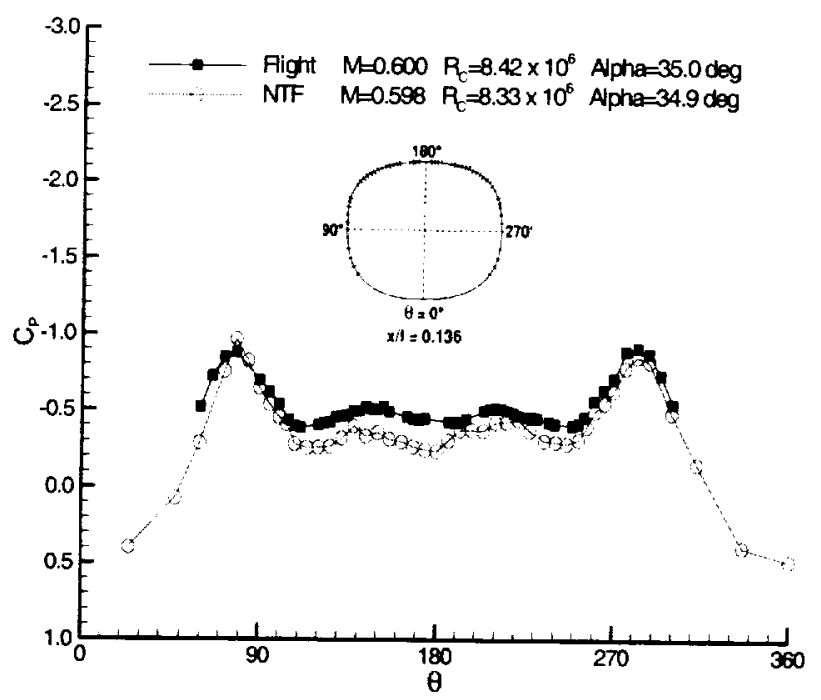

11b) $\alpha \approx 35^{\circ}$

Figure 11: $M=0.6$ NTF to Flight Forebody Pressure Distributions $30^{\circ}<\alpha<40^{\circ}$

A limited set of higher Reynolds number data were obtained at $M \approx 0.6$ during the NTF test for comparison with flight. Figures 11a through 11c have test conditions of $M \approx 0.6, R_{C} \approx 8.2$ million, and $\alpha \approx 30^{\circ}, 35^{\circ}, 40^{\circ}$ respectively. These pressure distributions exhibit similar characteristics as seen in the previous figures for flight Reynolds numbers of 5 to 6 million at lower Mach numbers, however there is a larger offset between the NTF and the flight data in the vicinity of the forebody vortices. This offset between the pressure distributions appears to remain fairly consistent over the limited angle of attack range shown in figure 11, and would most likely be attributable to the differences in the state of the boundary layers affecting separation locations on the leeward side of the forebody.

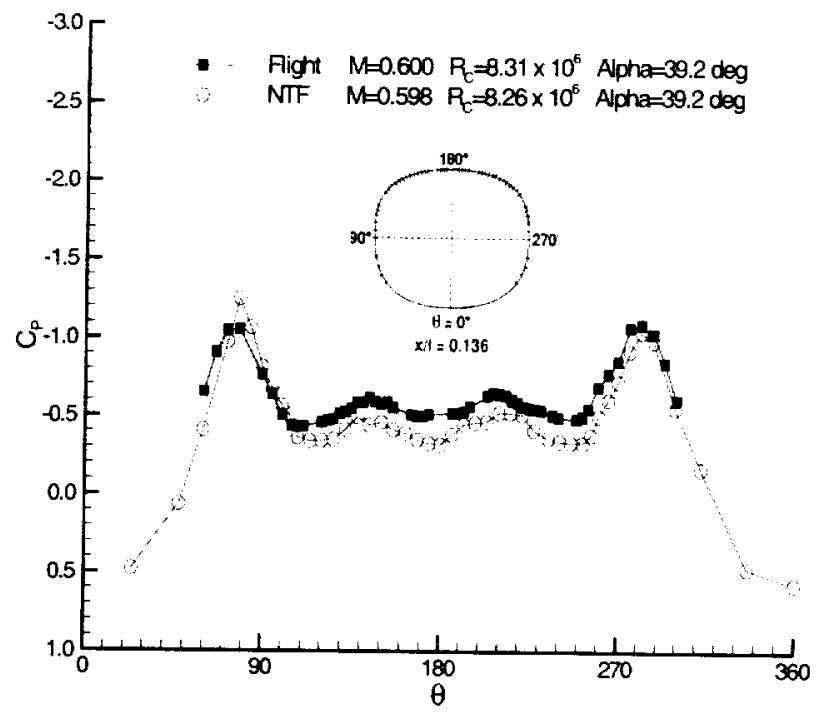

11c) $\alpha \approx 40^{\circ}$

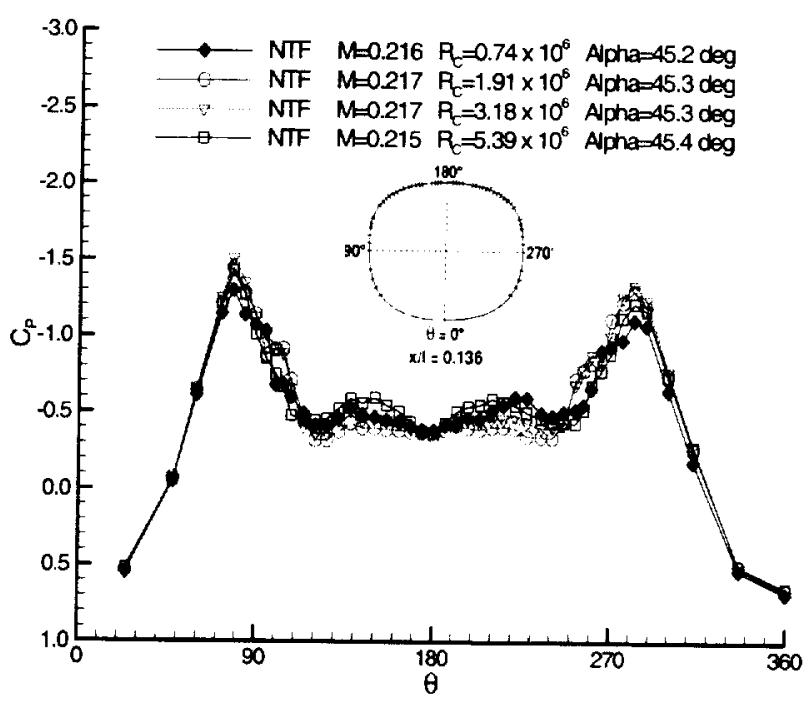

12a) $\alpha \approx 45^{\circ}$

Figure 12: Reynolds Number Effects on Forebody Pressures $\alpha \approx 45^{\circ}$ and $66^{\circ}$

Reynolds Number Effects on the Forebody Flow A unique advantage of testing in the NTF was the ability to study the X-29 over a large range of Reynolds numbers. Figure 12 shows forebody pressure data for the NTF model at chord Reynolds numbers ranging from 0.7 to 5.4 million. Figures 12a and 12b have a test Mach number of approximately 0.22 and angles of attack of approximately $45^{\circ}$ and $66^{\circ}$ respectively. All these data were obtained without fixing transition on the $1 / 16^{\text {th }}$ scale NTF model. As shown in Figure 13 the Reynolds numbers based on forebody diameter $\left(\operatorname{Re}_{\mathrm{D}}\right)$ in Lamont's criteria range from a laminar boundary layer state to a fully turbulent boundary layer state.? 


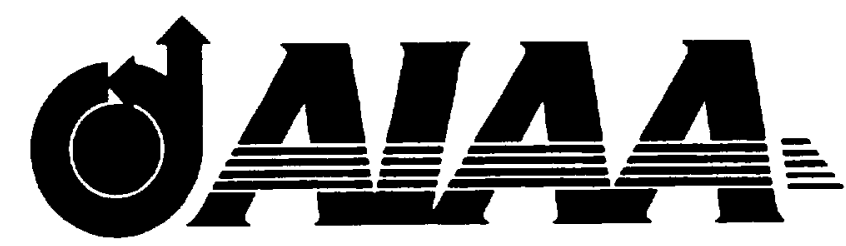

AIAA-2003-0752

X-29 High Alpha Test in the National Transonic Facility (Invited)

Pamela J. Underwood, ViGYAN, Inc.

Hampton, VA 23666

Lewis R. Owens, Richard A. Wahls, and Susan Williams

NASA Langley Research Center

Hampton, VA 23681

41st AIAA Aerospace Sciences Meeting \& Exhibit 6 - 9 January 2003

Reno, Nevada

For permission to copy or republish, contact the American Institute of Aeronautics and Astronautics 1801 Alexander Bell Drive, Suite 500, Reston, VA 20191-4344 


\title{
X-29 High Alpha Test in the National Transonic Facility
}

\author{
Pamela J. Underwood* \\ ViGYAN, Inc., Hamption, VA 23666
}

Lewis R. Owens', Richard A. Wahls', Susan Williams

NASA Langley Research Cente:, Hampton, VA 2368!

\begin{abstract}
$\underline{\text { Abstract }}$
This paper describes the $\mathrm{X}-29 \mathrm{~A}$ research program at the National Transonic Facility. This wind tunnel test leveraged the X-29A high alpha flight test program by enabling ground-to-flight correlation studies with an emphasis on Reynolds number effects. The background and objectives of this test program, as well as the comparison of high Reynolds number wind tunnel data to X-29A flight test data are presented. The effects of Reynolds number on the forebody pressures at high angles of attack are also presented. The purpose of this paper is to document this test and serve as a reference for future ground-toflight correlation studies, and high angle-of-attack investigations. Good ground-to-flight correlations were observed for angles of attack up to $50^{\circ}$, and Reynolds number effects were also observed.
\end{abstract}

Nomenclature

\begin{tabular}{|c|c|}
\hline $\mathrm{c}$ & mean aerodynamic chord, in \\
\hline $\mathrm{C}_{\mathrm{N}}$ & normal force coefficient \\
\hline $\mathrm{C}_{\mathrm{P}}$ & pressure coefficient \\
\hline $\mathrm{C}_{\mathrm{Y}}$ & side force coefficient \\
\hline DARPA & $\begin{array}{c}\text { Defense Advanced Research } \\
\text { Projects Agency }\end{array}$ \\
\hline $\mathrm{ESP}$ & electronically scanned pressure \\
\hline $\mathrm{F}$ & degrees Fahrenheit \\
\hline $\mathrm{l}$ & fuselage or body length, in \\
\hline $\mathrm{M}$ & Mach number \\
\hline $\mathrm{NTF}$ & National Transonic Facility \\
\hline $\mathrm{P}_{1}$ & total pressure, psi \\
\hline $\mathrm{R}_{\mathrm{C}}$ & $\begin{array}{c}\text { Reynolds number based on mean } \\
\text { aerodynamic chord }\end{array}$ \\
\hline $\mathrm{Re}_{\mathrm{D}}$ & $\begin{array}{c}\text { Reynolds number based on } \\
\text { forebody diameter }\end{array}$ \\
\hline $\mathrm{S}$ & Wing reference area, in ${ }^{2}$ \\
\hline $\mathrm{T}_{\mathrm{l}}$ & total temperature, ${ }^{\circ} \mathrm{F}$ \\
\hline $\mathrm{USAF}$ & United States Air Force \\
\hline $\mathrm{X}$ & axial distance from nose apex, in \\
\hline$\alpha$ & angle of attack, deg \\
\hline$\theta$ & circumferential angle, deg \\
\hline
\end{tabular}

Research Engineer, Member AIAA

1 Aerospace Engineer. Flow Physics and Control Branch, Senior Member AIAA

' Asst. Head, Configuration Aerodynamics Branch, Associate Fellow AIAA

\$ Aerospace Engineer

This material is declared work of the U.S. Government and is not subject to copyright protection in the United States.

\section{Introduction}

A joint research program to investigate the high angle-of-attack performance potential of the X-29A forward swept wing fighter commenced in the 1980's. Primary partners in this joint program were NASA, Grumman Aerospace, the United States Air Force (USAF), and the Defense Advanced Research Projects Agency (DARPA). During the high angleof-attack flight test, data were obtained to support aerodynamics, flow visualization, control systems, handling qualities, and maneuverability research. A more extensive description of this flight program may be found in reference 1 . The National Transonic Facility (NTF) X-29 High Alpha test was established to augment this flight research program by enabling ground-to-flight correlation studies with emphasis on Reynolds number effects. Portions of the data from this wind tunnel test have been previously published in related articles. ${ }^{2,3}$ The purpose of this paper is to further document this test and serve as a reference for future ground-to-flight correlation studies, and high angle-of-attack investigations.

\section{Aircraft Description}

The X-29A is a single place research airplane with a $29.27^{\circ}$ forward leading edge sweep wing, close coupled variable incidence canards, and full span dual hinged flaperons. ${ }^{4}$ The Grumman Aerospace designed X-29A is shown in figure 1 . The forward swept wing is an aeroelastically tailored composite structure with a supercritical airfoil and a fixed leading edge. A 75-inch long nose boom, and 24inch long nose strakes are positioned at the nose apex. Side and bottom views of the nose apex are shown in figure 2. 


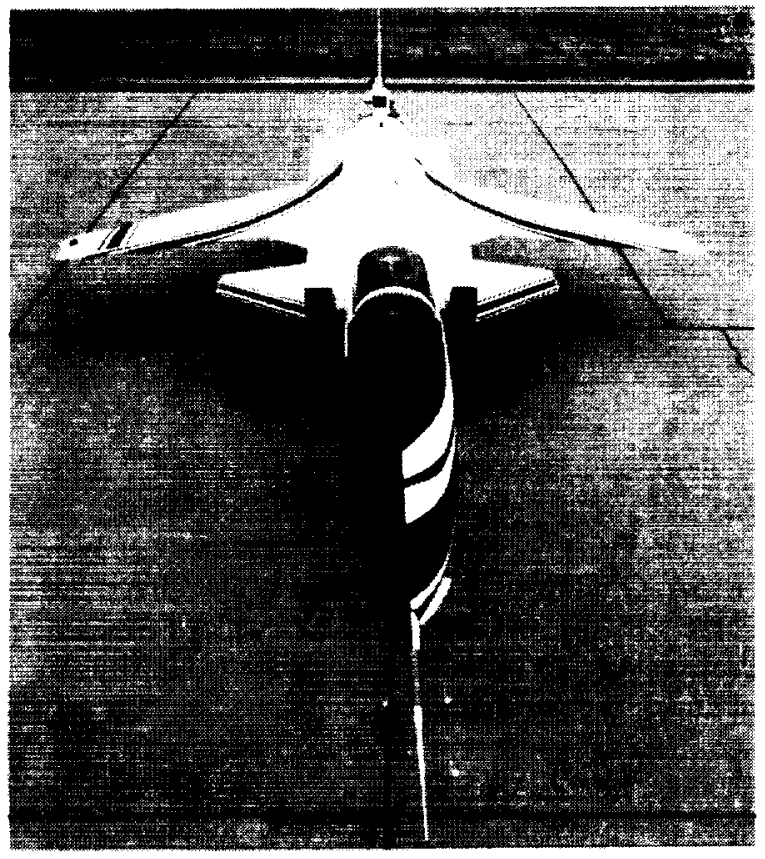

Figure 1: Grumman Aerospace X-29A
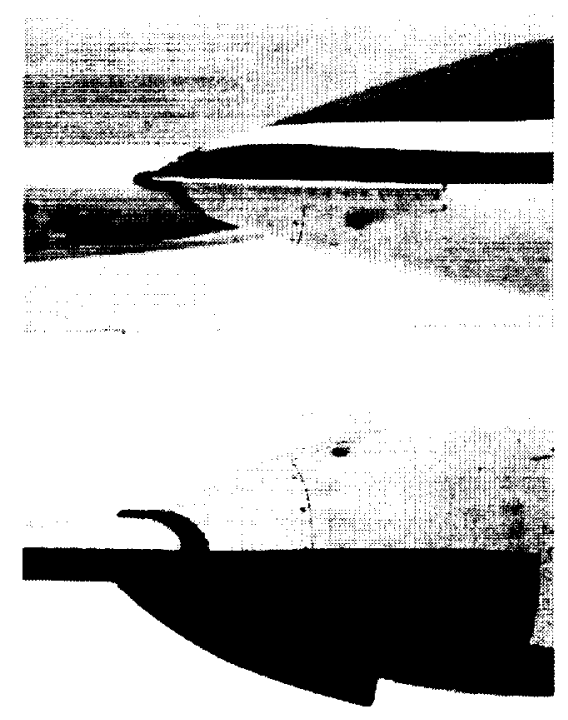

Figure 2: Side and Bottom View of Nose Apex

The nose boom tapered from a 0.88 -inch diameter at the tip to a 3.5-inch diameter at the nose apex, and the nose strakes were 1.5 inches wide at the nose apex and 2.5 inches wide at the downstream end. As shown in figure 3 the research airplane was instrumented with four circumferential rows of static pressure orifices.

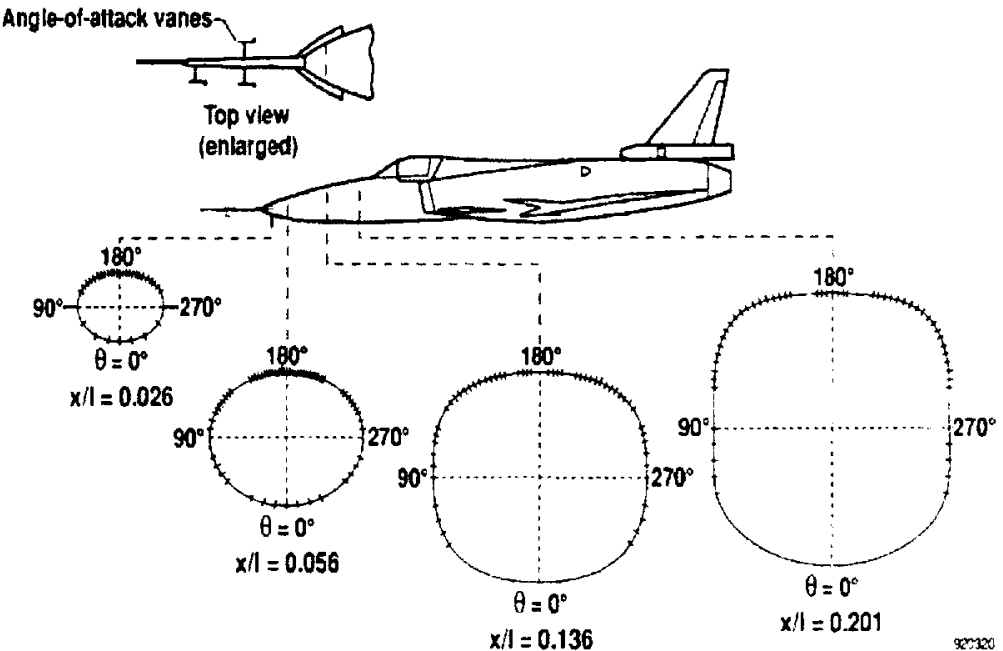

Figure 3: X-29A Research Aircraft Forebody Pressure Locations

The distribution of these static pressure rows is also shown in figure 3 , where $0^{\circ}$ is the windward side of the fuselage, $90^{\circ}$ is the starboard side, and $180^{\circ}$ is the leeward side. In addition to these static pressure orifices on the forebody, the research airplane was also instrumented with three angle of attack vanes and one angle of sideslip vane on the nose boom.

\section{Facility Description}

The NTF is a unique transonic wind tunnel designed to conduct full-scale flight Reynolds number testing through the use of high pressures and cryogenic temperatures. This is a fan driven, closed circuit wind tunnel with an 8.2-foot by 8.2-foot and 25-foot long test section with a slotted ceiling and floor. A planform view of the tunnel is provided in figure 4 .

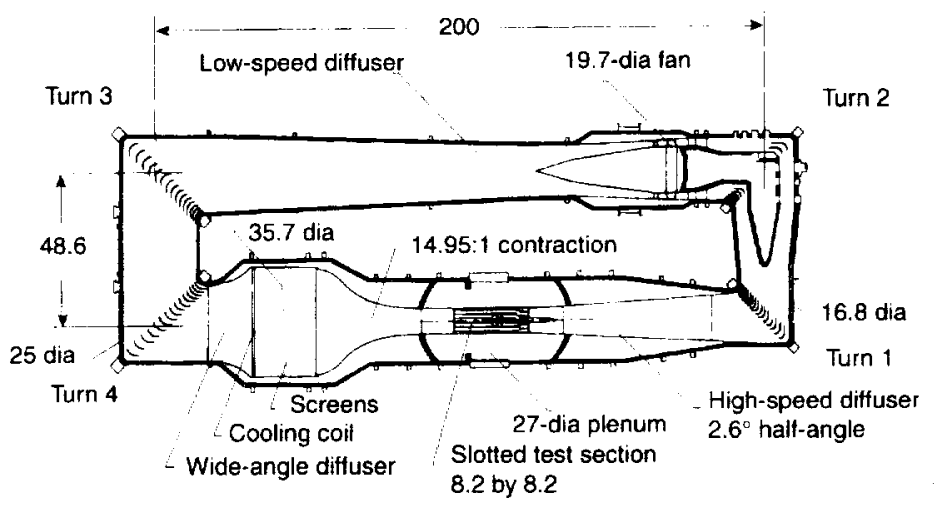

Figure 4: Planform View of the NTF

The tunnel operates using either dry air or gaseous nitrogen as the test medium. During air operations the tunnel pressure is used to control Reynolds number, while in the cryogenic nitrogen mode the tunnel temperature and pressure are used to control Reynolds number. The NTF affords a test 
environment in which the Mach number and chord Reynolds number are identical for the scale model in the test section and the full-scale aircraft in flight. The NTF is capable of an absolute pressure range from 15 psia to $125 \mathrm{psia}$, a temperature range from $-320^{\circ} \mathrm{F}$ to $150^{\circ} \mathrm{F}$, a Mach number range from 0.2 to 1.2 , and a maximum Reynolds number of $146 \times 10^{6}$ per $\mathrm{ft}$ at Mach 1. Typical tests use a temperature range from $-250^{\circ} \mathrm{F}$ to $120^{\circ} \mathrm{F}$. A more extensive facility description can be found in reference 5 .

\section{NTF X-29 Test Program}

The primary test objectives were to compare the NTF high Reynolds number forebody pressure data to the data obtained during the X-29A high alpha flight test, and to assess the Reynolds number effects on the forebody flow at high angles of attack. The effect of fixing transition on the forebody was also studied during this test program.

\section{$1 / 16^{\text {th }}$ Scale X-29 Model}

The NTF X-29 model is a $1 / 16^{\text {th }}$ scale representation of the research airplane. All of the components of the $\mathrm{X}-29 \mathrm{~A}$ research airplane were accurately scaled for the NTF model except for the thickness of the nose strakes. At $1 / 16^{\text {th }}$ scale the model nose strakes should have been 0.0075 inches thick, but were actually 0.03 inches thick due to NTF model strength requirements. Pertinent model geometry is given in figure 5 .
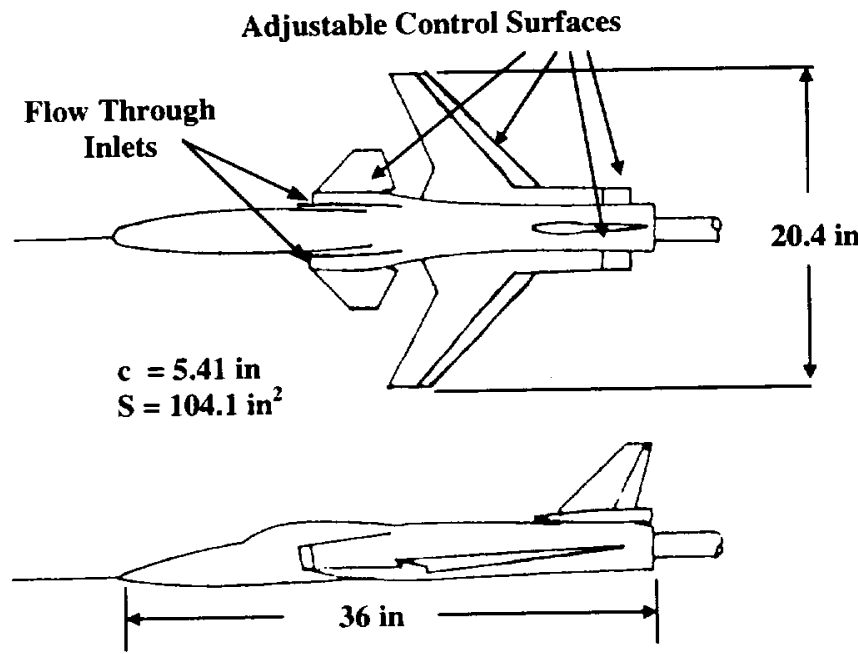

Figure 5: $1 / 16^{\text {th }}$ Scale X-29 Model Geometry
The $1 / 16^{\text {th }}$ scale NTF model featured flow through inlets positioned on either side of the forebody just forward of the canards that combined to form a single exhaust at the back of the model. A flow shield was included to isolate the balance from the interior duct flow in this model.

The contour tolerance of the wing, canard, and vertical tail was \pm 0.002 inches. The fuselage torebody tolerance was \pm 0.004 inches, while the semaining fuselage tolerance was approximately $\because 0.004$ inches to \pm 0.006 inches. The model was huilt of $18 \%$ nickel maraging steel ( $\mathrm{C}$ type) with a surface finish of approximately 10 microinches (RMS). The model was composed of separable components to allow testing of multiple configurations. The flaperons, aft body strakes, rudder, and canards were all designed to be set at discrete angles. The $1 / 16^{\text {th }}$ scale NTF X-29 model is shown in figure 6 with all its control surface components. During this NTF test only the canard angle was varied. The model canard was designed to accommodate five discrete angle positions $\left(-20^{\circ}\right.$, $-25^{\circ},-30^{\circ},-35^{\circ},-60^{\circ}$ ), and was set to match the flight test conditions as closely as possible.

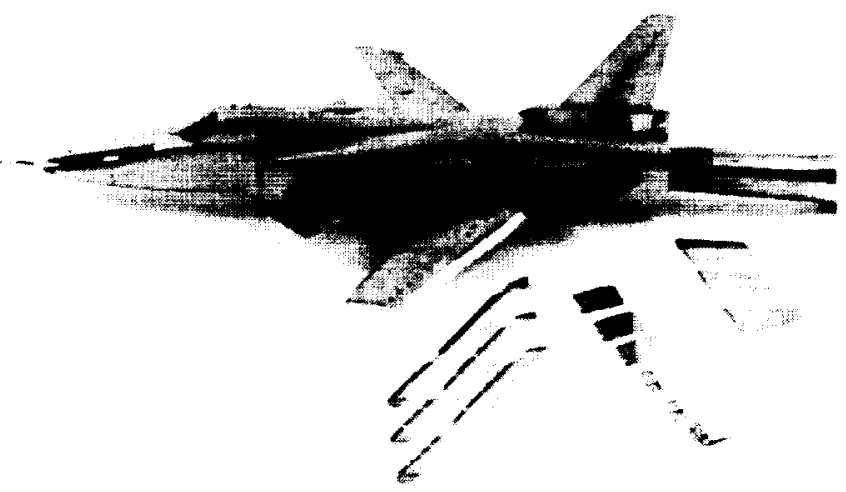

Figure 6: NTF X-29 Model with Control Surfaces

A unique high alpha sting was used with the X-29 model. This sting was designed to accommodate an angle of attack range from $-7^{\circ}$ to $74^{\circ}$ using three primary knuckle positions. A sketch of this high alpha sting showing the three possible knuckle positions is given in Figure 7. As seen in this sketch, only the second knuckle position keeps the model center of rotation aligned with the tunnel centerline, and positions \#1 and \#3 would present the model positions most susceptible for wall interference. Figure 8 shows the $1 / 16^{\text {th }}$ scale X-29 model mounted on the high alpha sting in the NTF test section. 


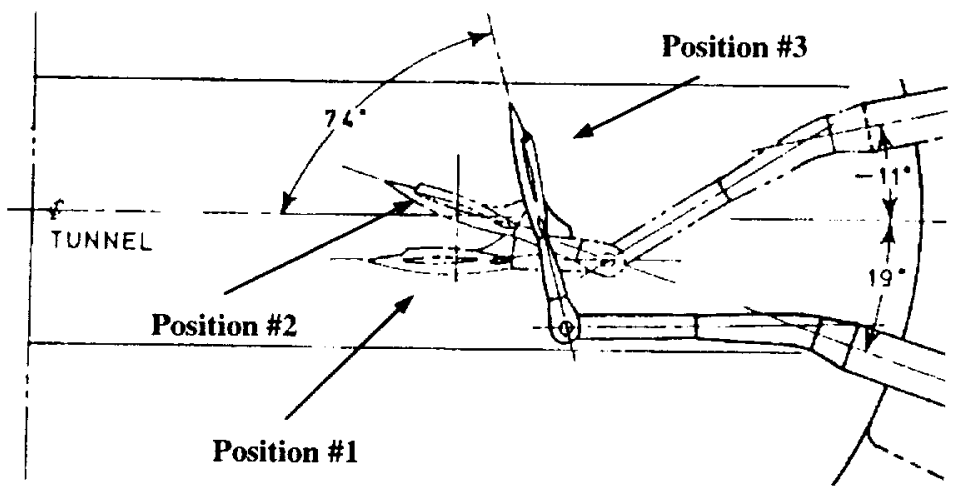

Figure 7: General Arrangement of NTF High Alpha Sting Depicting Three Knuckle Positions (Not to Scale)

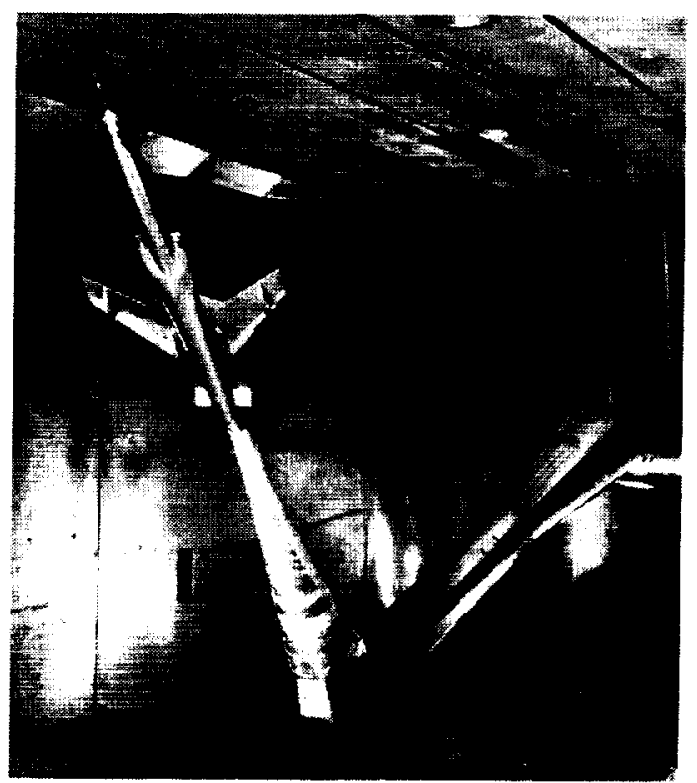

Figure 8: X-29 Model Mounted in NTF Test Section (Knuckle Position \#3)

Instrumentation and Measurement Corrections

The NTF model was instrumented with one circumferential row of static pressure orifices on the forebody at station $x / l=0.136$. This forebody location was chosen to correspond with one of the X-29A research airplane static pressure row locations (see figure 3 ). The circumferential distribution of the model static pressure orifices was also positioned to match the research airplane as closely as possible. Table 1 gives the circumferential pressure orifice locations for both the X-29 research airplane and the $X-29$ NTF model at $X / l=0.136$. Again, $0^{\circ}$ is the windward side of the fuselage, $90^{\circ}$ is the starboard side, and $180^{\circ}$ is the leeward side.

The NTF model forebody pressure data were obtained through the use of one internal 48 port electronically scanned pressure (ESP) module with a full-scale pressure range of $\pm 15 \mathrm{psid}$. The quoted (worst case) accuracy of the ESP module was approximately 0.20 percent of full scale or \pm 0.030 psi $\left(C_{P}\right.$ variation \pm 0.06 at the lowest dynamic pressure condition). For reference, the X-29A high alpha flight test forebody pressure data were obtained using $\pm 1.5 \mathrm{psi}$ differential pressure transducers with an estimated accuracy of approximately $\pm 0.007 \mathrm{psi}^{4}{ }^{4}$ The model aerodynamic force and moment data were obtained with a six component unheated strain gage balance. The balance maximum load capacity and quoted accuracies are given in Table 2. The axial force and moment data acquired were inconsistent, and deemed corrupt. These data show signs of interference on the balance most likely due to the tightly packed instrumentation within the model. Normal and side force data were less sensitive to this adverse effect, and are presented herein. The main objective was to compare forebody pressures with available flight data.

Table 1: Circumferential Static Pressure Locations, $\mathbf{x} / \mathbf{l}=\mathbf{0 . 1 3 6}$

\begin{tabular}{|c|c|}
\hline $\begin{array}{c}\text { NTF } \\
\theta(\mathrm{deg})\end{array}$ & $\begin{array}{c}\text { Flight } \\
\theta(\mathrm{deg})\end{array}$ \\
\hline 24.2 & $\mathrm{n} / \mathrm{a}$ \\
\hline 47.6 & $\mathrm{n} / \mathrm{a}$ \\
\hline 59.6 & 60.0 \\
\hline $\mathrm{n} / \mathrm{a}$ & 66.0 \\
\hline 72.0 & 72.0 \\
\hline 77.9 & 78.0 \\
\hline 83.9 & $\mathrm{n} / \mathrm{a}$ \\
\hline 89.8 & 90.0 \\
\hline 95.0 & 95.0 \\
\hline 99.9 & 100.0 \\
\hline 103.7 & 105.0 \\
\hline 107.7 & 108.0 \\
\hline 114.1 & 111.1 \\
\hline 119.9 & 120.0 \\
\hline 125.9 & 126.0 \\
\hline $\mathrm{n} / \mathrm{a}$ & 129.0 \\
\hline 131.9 & 132.0 \\
\hline $\mathrm{n} / \mathrm{a}$ & 135.0 \\
\hline 138.0 & 138.0 \\
\hline $\mathrm{n} / \mathrm{a}$ & 141.0 \\
\hline 143.9 & 144.0 \\
\hline $\mathrm{n} / \mathrm{a}$ & 147.0 \\
\hline 150.0 & 150.0 \\
\hline $\mathrm{n} / \mathrm{a}$ & 153.0 \\
\hline 155.9 & 156.0 \\
\hline 162.1 & 165.0 \\
\hline 167.9 & 168.0 \\
\hline $\mathrm{n} / \mathrm{a}$ & 171.0 \\
\hline 174.0 & 174.0 \\
\hline 180.0 & $\mathrm{n} / \mathrm{a}$ \\
\hline & \\
\hline
\end{tabular}

\begin{tabular}{|c|c|}
\hline $\begin{array}{c}\text { NTF } \\
\theta(\mathrm{deg})\end{array}$ & $\begin{array}{c}\text { Flight } \\
\theta(\mathrm{deg})\end{array}$ \\
\hline 185.9 & 186.0 \\
\hline $\mathrm{n} / \mathrm{a}$ & 189.0 \\
\hline 191.9 & 192.0 \\
\hline 197.7 & 195.0 \\
\hline 203.6 & 204.0 \\
\hline $\mathrm{n} / \mathrm{a}$ & 207.0 \\
\hline 209.8 & 210.0 \\
\hline $\mathrm{n} / \mathrm{a}$ & 213.0 \\
\hline 215.5 & 216.0 \\
\hline $\mathrm{n} / \mathrm{a}$ & 219.0 \\
\hline 221.4 & 222.0 \\
\hline $\mathrm{n} / \mathrm{a}$ & 225.0 \\
\hline 227.3 & 228.0 \\
\hline $\mathrm{n} / \mathrm{a}$ & 231.0 \\
\hline 234.7 & 234.0 \\
\hline $\mathrm{n} / \mathrm{a}$ & 237.0 \\
\hline 240.5 & 240.0 \\
\hline 246.2 & 249.0 \\
\hline 252.3 & 252.0 \\
\hline $\mathrm{n} / \mathrm{a}$ & 255.0 \\
\hline 260.3 & 260.0 \\
\hline 265.2 & 265.0 \\
\hline 270.0 & 270.0 \\
\hline 276.0 & 276.0 \\
\hline 288.0 & 288.0 \\
\hline $\mathrm{n} / \mathrm{a}$ & 294.5 \\
\hline 299.5 & 300.0 \\
\hline 336.1 & $\mathrm{n} / \mathrm{a}$ \\
\hline 360.0 & $\mathrm{n} / \mathrm{a}$ \\
\hline & \\
\hline
\end{tabular}


Table 2: NTF Balance Load Capacity

\begin{tabular}{|c|c|c|}
\hline Component & $\begin{array}{c}\text { Maximum } \\
\text { Load }\end{array}$ & $\begin{array}{c}\text { Full-Scale } \\
\text { Accuracy }\end{array}$ \\
\hline Normal Force & $\pm 2500 \mathrm{lb}$ & $0.10 \%$ \\
\hline Axial Force & $\pm 350 \mathrm{lb}$ & $0.26 \%$ \\
\hline Pitching Moment & $\pm 5000 \mathrm{in}-\mathrm{lb}$ & $0.11 \%$ \\
\hline Rolling Moment & $\pm 2500 \mathrm{in}-\mathrm{lb}$ & $0.40 \%$ \\
\hline Yawing Moment & $\pm 4000 \mathrm{in}-\mathrm{lb}$ & $0.18 \%$ \\
\hline Side Force & $\pm 1000 \mathrm{lb}$ & $0.35 \%$ \\
\hline
\end{tabular}

Space limitations inside the $1 / 16^{\text {th }}$ scale NTF model due to the flow shield around the balance, and the pressure instrumentation prohibited the use of an on board accelerometer to measure model angle-ofattack. These angles were measured using an arcsector mounted accelerometer package corrected for sting bending using the balance loads and support sting deflection sensitivities. These angle of attack measurements had an estimated accuracy of $\pm 0.1^{\circ}$. Further information on the tunnel instrumentation, data recording, and the data reduction algorithms is provided in reference 6 . The data herein were not corrected for wall interference, support tare and interference, and tunnel upflow.

\section{Test Conditions}

The NTF test program was designed to match Mach number, chord Reynolds number, and angle of attack with existing X-29A high alpha flight-test data. The test had a Mach number range from 0.22 to 0.25 at Reynolds numbers based on mean aerodynamic chord ranging from 0.7 to 6.8 million, and an angleof-attack range from 28 to 68 degrees. A limited set of data were acquired at 0.6 Mach number, Reynolds numbers ranging from 1.6 to 8.3 million, and an angle of attack range from 28 to 42 degrees. The low Reynolds number testing ( $R_{C} \leq 3.3$ million) in air was conducted at total pressures ranging from approximately 16 to $75 \mathrm{psia}$, and total temperatures ranging from 75 to $100^{\circ} \mathrm{F}$. The high Reynolds number testing $\left(R_{C} \geq 5\right.$ million) in gaseous nitrogen had total pressures ranging from approximately 30 to $85 \mathrm{psia}$, with total temperatures ranging from -55 to $-200^{\circ} \mathrm{F}$. Overall the dynamic pressure ranged from approximately 70 to $800 \mathrm{psf}$.

\section{$\underline{\text { Results and Discussion }}$}

\section{Tunnel to Flight Pressure Data Comparison}

A comparison of the forebody pressure distributions obtained from the NTF and flight is given in figures 9 through 11. These data are plotted as the coefficient of pressure $\left(C_{P}\right)$ versus radial forebody location $(\theta)$ in degrees. Once again $0^{\circ}$ represents the windward side of the fuselage, $90^{\circ}$ is the starboard side, and $180^{\circ}$ is the leeward side. All the data in these figures were obtained without fixing transition on the $1 / 16^{\text {th }}$ scale NTF model. Figures $9 a$ and $9 b$ are for test conditions of $0.25 \mathrm{Mach}$ number (M). Reynolds number based on mean aerodynamic chord $\left(R_{C}\right)$ of approximately 6.6 million, and angles of attack $(\alpha)$ of approximately 30 and 35 degrees respectively. Figures $9 \mathrm{c}$ and $9 \mathrm{~d}$ are for test conditions of $M \approx 0.22, R_{C} \approx 5.6$ million, and $\alpha \approx 40^{\circ}$ and $45^{\circ}$, respectively.

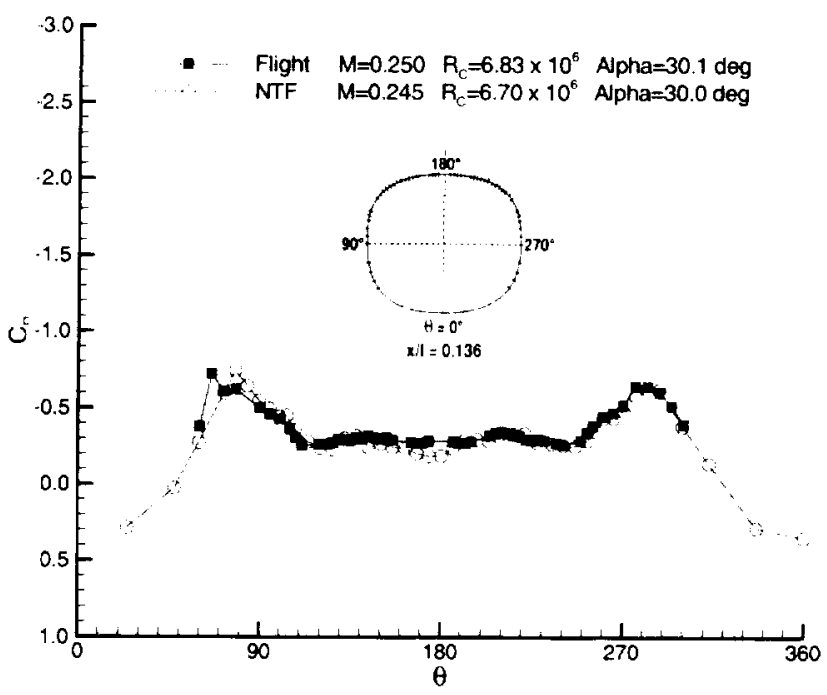

9a) $\alpha \approx 30^{\circ}$

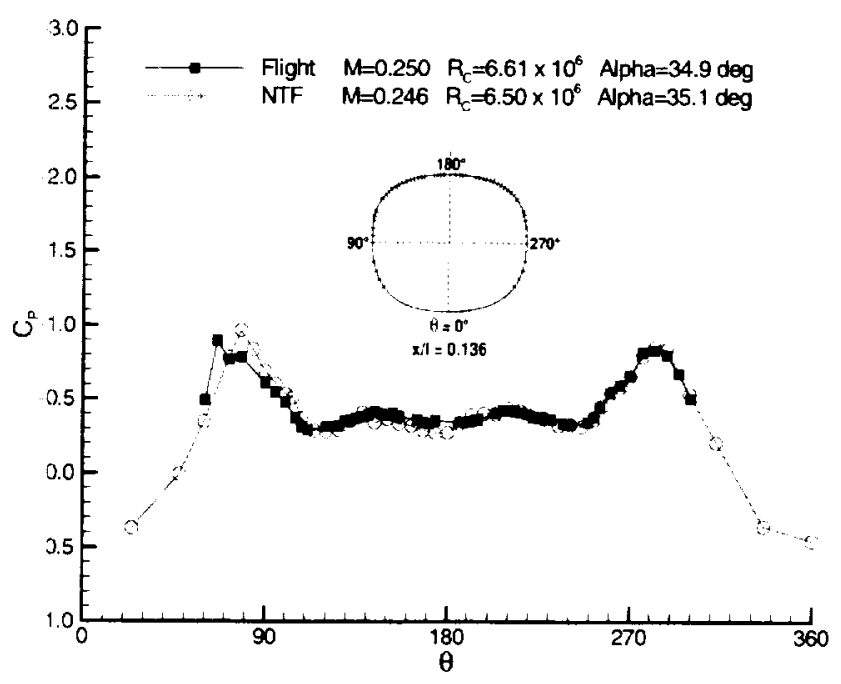

9b) $\alpha \approx 35^{\circ}$

Figure 9: NTF to Flight Forebody Pressure Distributions for $30^{\circ}<\alpha<45^{\circ}$ at $x /=0.136$ 


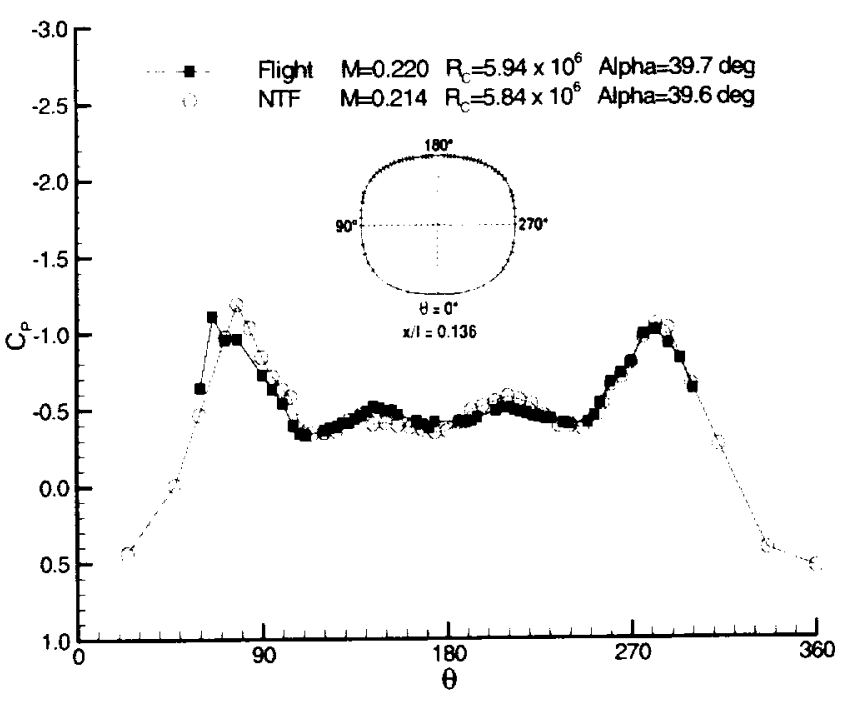

9c) $\alpha \approx 40^{\circ}$

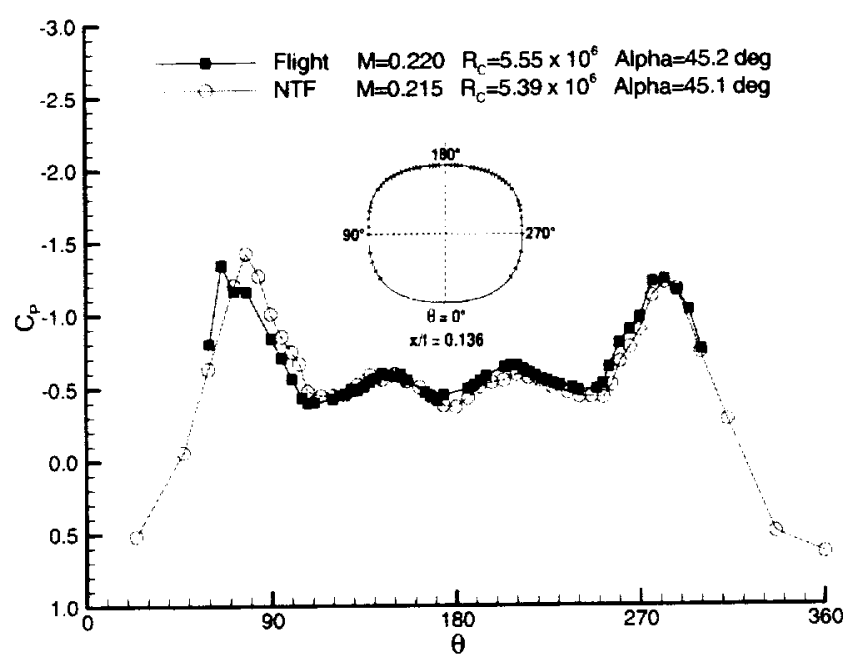

9d) $\alpha \approx \mathbf{4 5}^{\circ}$

Figure 9: Concluded

The primary suction peaks at $\theta \approx 70^{\circ}$ and $290^{\circ}$ indicate the local acceleration of the attached flow around this highly curved region of the forebody surface. After reaching the maximum forebody width, the flow begins to decelerate as it approaches the leeward side of the forebody. This deceleration continues until the flow separates at $\theta \approx 110^{\circ}$ and $250^{\circ}$. Finally, the effects of the vortices due to the forebody are noted by the secondary suction peaks at $\theta \approx 150^{\circ}$ and $210^{\circ}$. This type of pressure distribution is typical of that seen in previous forebody studies.

An approximate $10^{\circ}$ off set exists between the NTF and the flight data on the starboard suction peak at

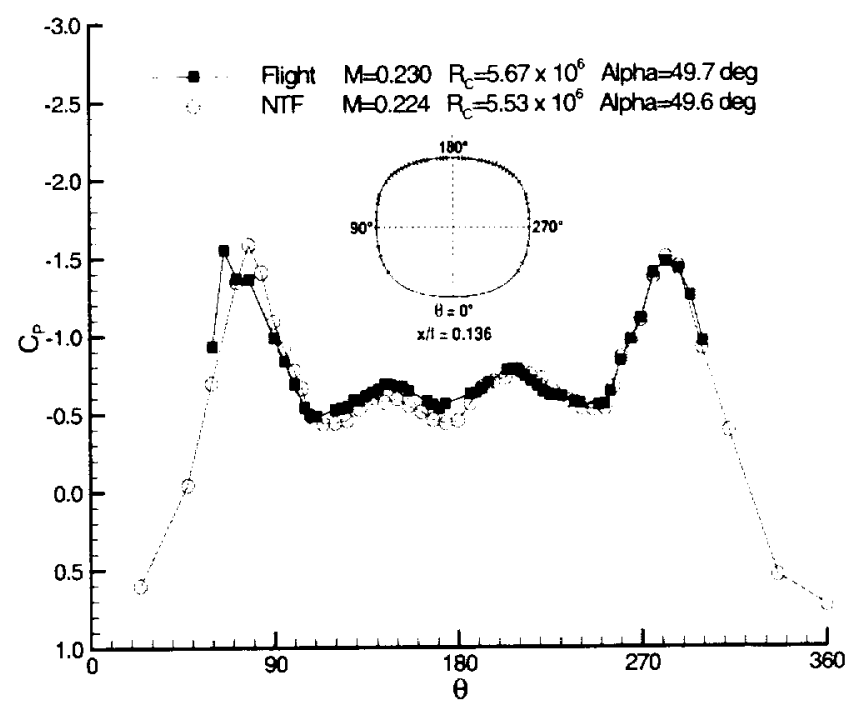

10a) $\alpha \approx 50^{\circ}$

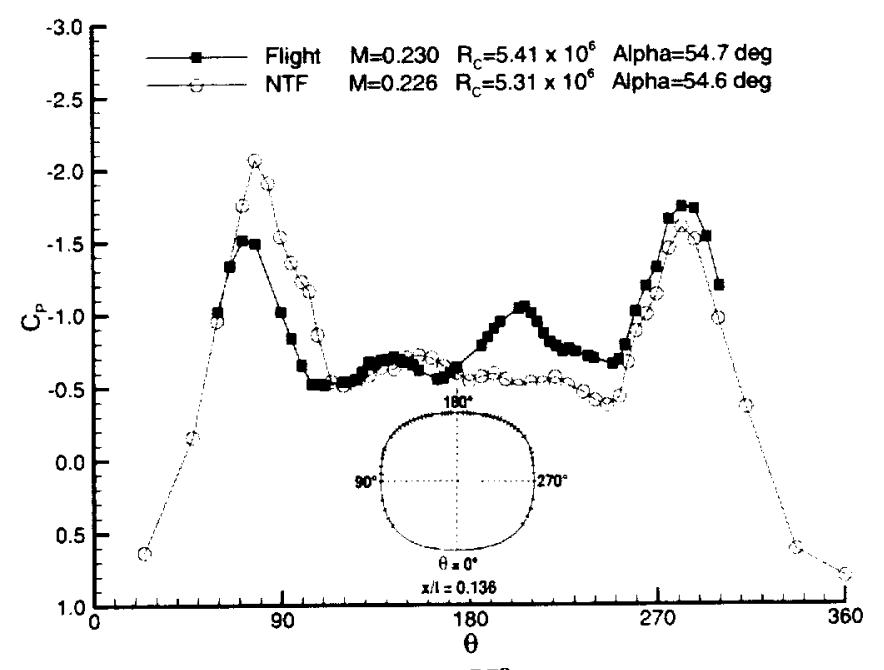

10b) $\alpha \approx 55^{\circ}$

\section{Figure 10: NTF to Flight Forebody Pressure Distributions $50^{\circ}<\alpha<66^{\circ}$}

$\theta \approx 70^{\circ}$. Since this off set remains fairly constant and exists in all of the forebody pressure data examined, it is most likely attributed to a slight geometric difference in the forebody cross-sectional geometry between the $1 / 16^{\text {th }}$ scale NTF model and the X-29A research airplane. As expected, all the pressure distributions remain fairly symmetric in this alpha range $\left(30^{\circ}<\alpha<45^{\circ}\right)$, and generally increase with angle of attack. Overall there is a good correlation between the NTF and flight forebody pressure distributions for angles of attack from 30 to 45 degrees.

Figures 10a through 10d have test conditions of $\mathrm{M} \approx 0.23, \mathrm{R}_{\mathrm{C}} \approx 5.4$ million, and $\alpha \approx 50^{\circ}, 55^{\circ}, 59^{\circ}$, and $66^{\circ}$, respectively. There is still reasonable agreement 


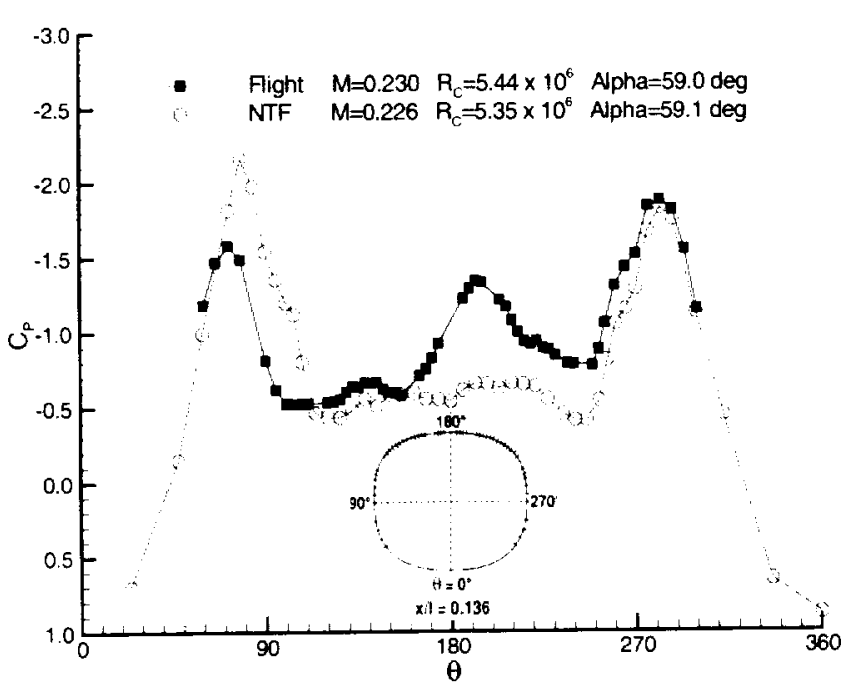

10c) $\alpha \approx 59^{\circ}$

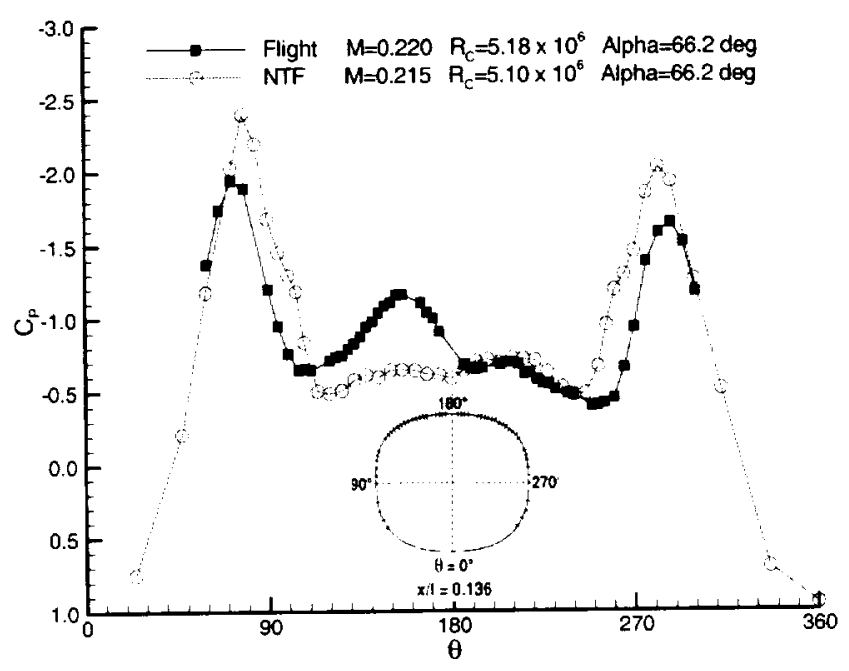

10d) $\alpha \approx 66^{\circ}$

Figure 10: Concluded

between the NTF data and the flight data at $\alpha \approx 50^{\circ}$, but for angles of attack above $50^{\circ}$ there is an appreciable difference between the two pressure distributions. At $\alpha \approx 55^{\circ}$ a distinct asymmetry develops between the forebody vortices in the flight data as indicated by the asymmetric secondary suction peaks. The starboard vortex at $\theta \approx 140^{\circ}$ lifts away from the surface while the port vortex at $\theta \approx 210^{\circ}$ shifts closer to the forebody causing a higher secondary suction peak under the vortex core. The proximity of the port vortex to the forebody also influences the primary suction peak at $\theta \approx 290^{\circ}$, and ultimately results in a nose left yawing moment for the research airplane. The pressure distribution for the NTF model is more symmetric than the flight data at this same angle of attack with only a slight nose right yawing moment indication. The secondary suction peak under the port forebody vortex for the NTF data is less pronounced here than it has been at the lower angles of attack.

At $\alpha=59^{\circ}$ the asymmetry between the forebody cortices in the flight pressure distribution is more pronounced. and again a pressure distribution associated with the nose left tending yawing moment is observed. The NTF data at $\alpha \approx 59^{\circ}$ again is a more symmetric than that of the flight data with only a : light tendency toward a nose right yawing moment. The flight pressure distribution for $\alpha \approx 66^{\circ}$ indicate a change in asymmetry resulting in a nose right yawing moment for the research airplane. which is typical for very sensitive high Reynolds number forebody apex thow fields. ${ }^{28.11}$ The NTF data at $\alpha \approx 66^{\circ}$ maintain characteristics similar to $\alpha=59^{\circ}$, and unlike the flight data did not experience a change in yawing moment direction.

Overall these differences in the pressure distributions between the NTF and flight are most likely caused by the differences in both the boundary layer states, and the geometric modeling of the forebody apex. nose boom. and nose strakes. The differences in the boundary layers between the research airplane and the $1 / 16^{\text {th }}$ scale NTF model may be attributed to differences in the surface roughness between the two test articles. The NTF model had a very smooth surface finish (approximately 10 microinches), while the research airplane had longitudinal gaps and steps in the forebody due to instrumentation access panels that were located forward of the $x / 1=0.136$ pressure row. Other external equipment on the research airplane that could have affected the forebody flow especially at the higher angles of attack include an antenna, as well as the three angle of attack and one angle of sideslip vanes mounted on the nose boom. None of these access panels or other equipment was modeled on the $1 / 16^{\text {th }}$ scale NTF test article. When it is important to match high angle-of-attack flight conditions for this type of forebody flow field, then it is necessary to consider even the smallest geometric differences that may cause an asymmetry in the flow.

A source of error that may also contribute to the discrepancies observed between the NTF and flight data for $\alpha \geq 50^{\circ}$ would be the wall interference associated with using knuckle position \#3 on the high alpha sting. For this test, knuckle position $\# 3$ placed the model in the closest proximity to the walls and makes the pressure distributions more susceptible to wall interference. 


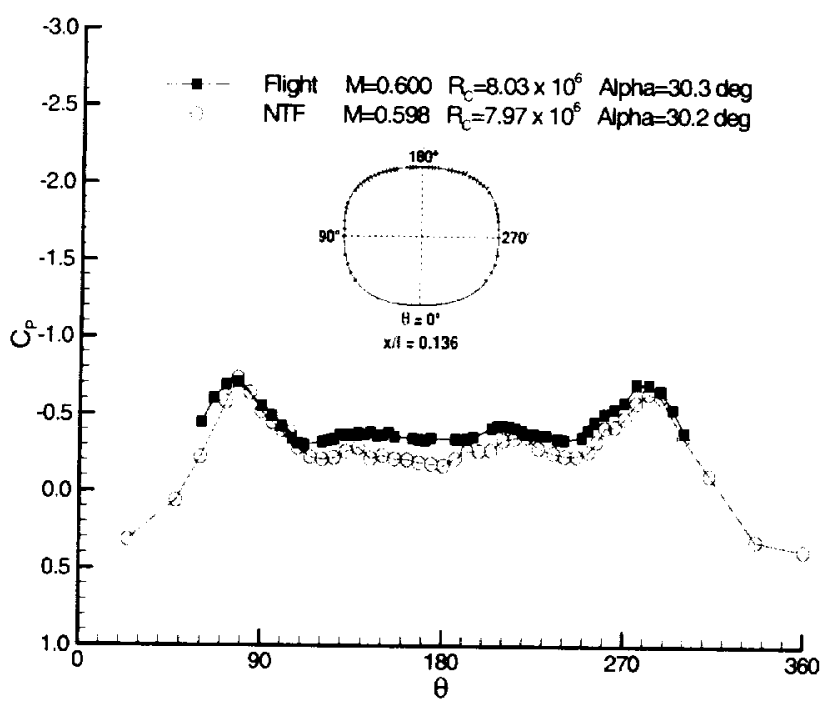

11a) $\alpha \approx 30^{\circ}$

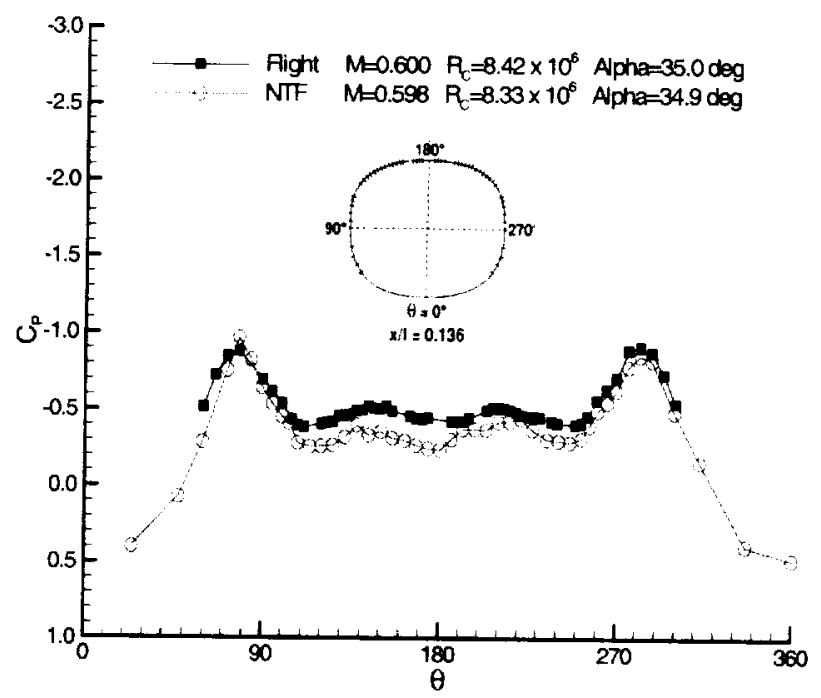

11b) $\alpha \approx 35^{\circ}$

Figure 11: $M=0.6$ NTF to Flight Forebody Pressure Distributions $30^{\circ}<\alpha<40^{\circ}$

A limited set of higher Reynolds number data were obtained at $M \approx 0.6$ during the NTF test for comparison with flight. Figures 11a through 11c have test conditions of $M \approx 0.6, R_{C} \approx 8.2$ million, and $\alpha \approx 30^{\circ}, 35^{\circ}, 40^{\circ}$ respectively. These pressure distributions exhibit similar characteristics as seen in the previous figures for flight Reynolds numbers of 5 to 6 million at lower Mach numbers, however there is a larger offset between the NTF and the flight data in the vicinity of the forebody vortices. This offset between the pressure distributions appears to remain fairly consistent over the limited angle of attack range shown in figure 11, and would most likely be attributable to the differences in the state of the boundary layers affecting separation locations on the leeward side of the forebody.

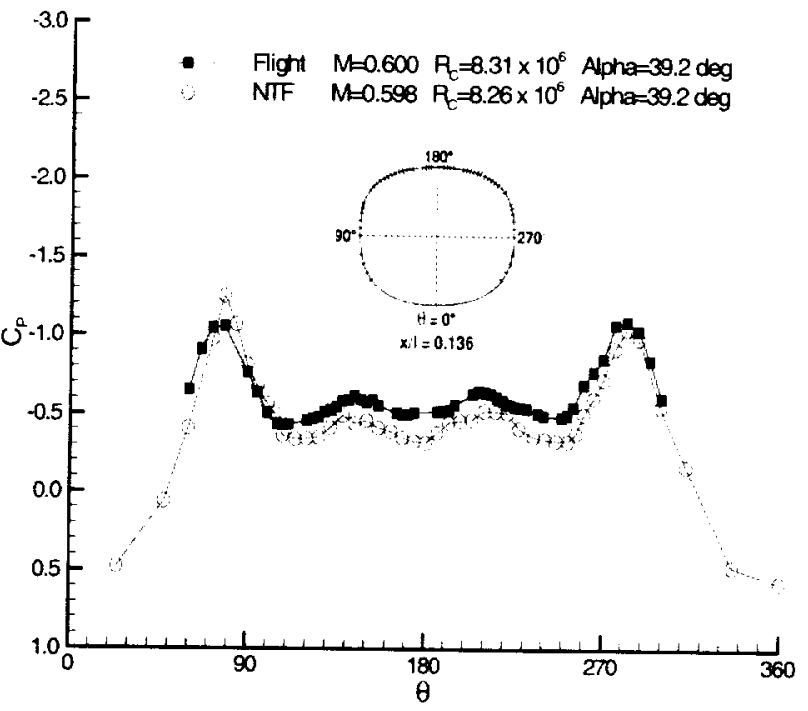

11c) $\alpha \approx 40^{\circ}$

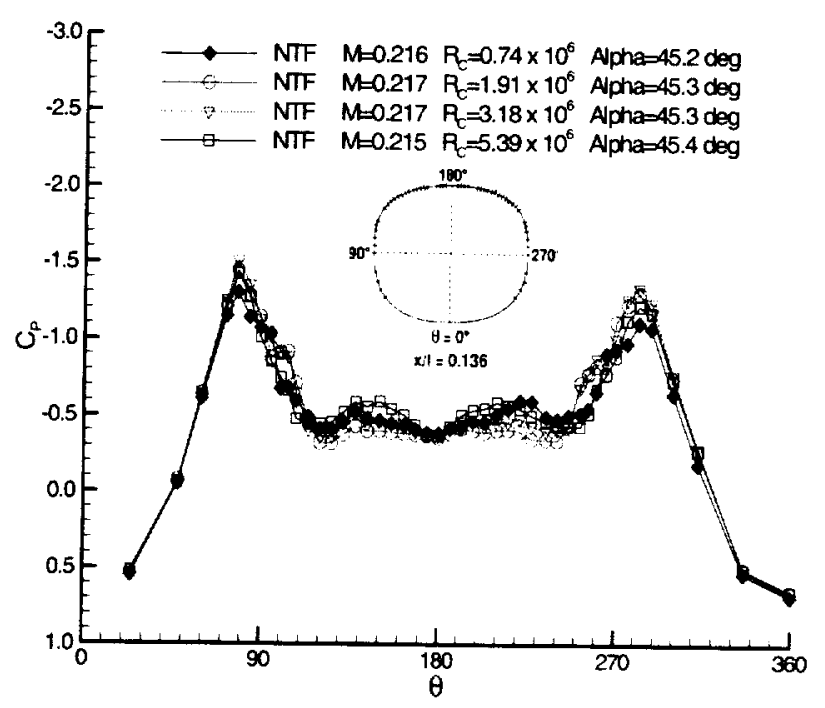

12a) $\alpha \approx 45^{\circ}$

Figure 12: Reynolds Number Effects on Forebody Pressures $\alpha \approx 45^{\circ}$ and $66^{\circ}$

Revnolds Number Effects on the Forebody Flow $A$ unique advantage of testing in the NTF was the ability to study the X-29 over a large range of Reynolds numbers. Figure 12 shows forebody pressure data for the NTF model at chord Reynolds numbers ranging from 0.7 to 5.4 million. Figures $12 \mathrm{a}$ and $12 \mathrm{~b}$ have a test Mach number of approximately 0.22 and angles of attack of approximately $45^{\circ}$ and $66^{\circ}$ respectively. All these data were obtained without fixing transition on the $1 / 16^{\text {th }}$ scale NTF model. As shown in Figure 13 the Reynolds numbers based on forebody diameter $\left(\mathrm{Re}_{\mathrm{D}}\right)$ in Lamont's criteria range from a laminar boundary layer state to a fully turbulent boundary layer state. 


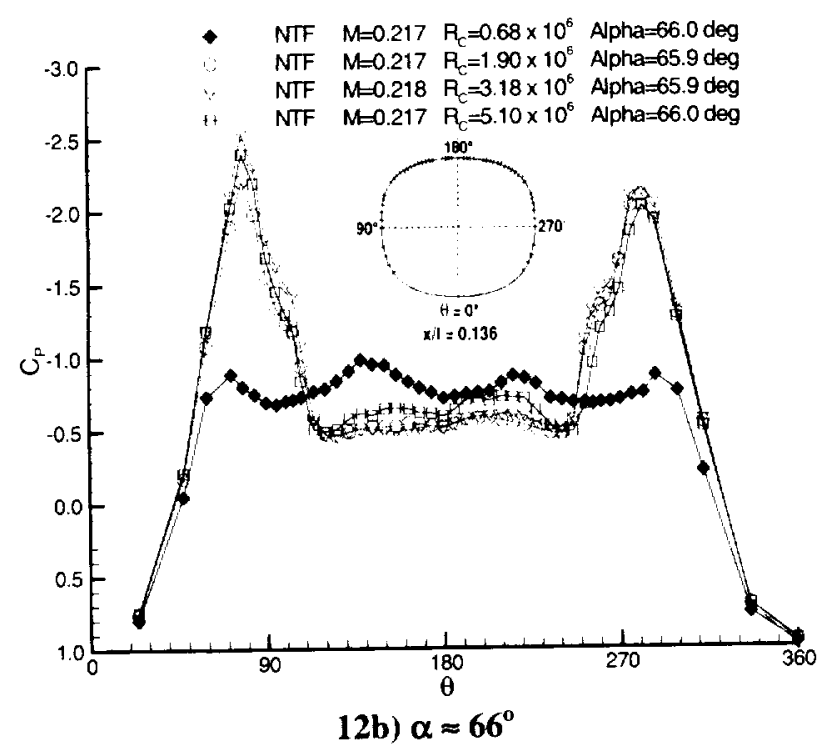

Figure 12: Concluded

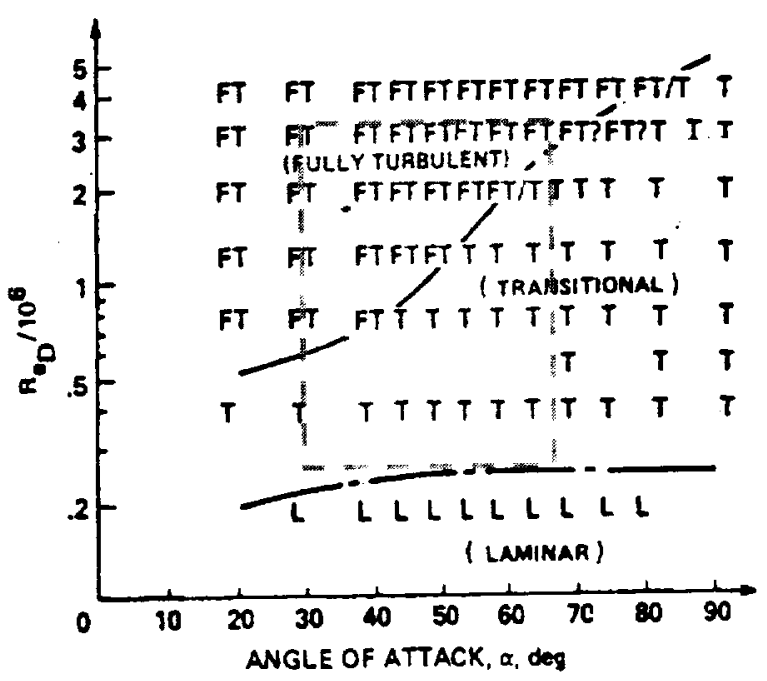

Figure 13: Lamont's Classification of ThreeMain Flow Regimes ${ }^{7}$

For reference, the ratio of the NTF model forebody diameter $(x /=0.136)$ to the mean aerodynamic chord is approximately $2 / 5$ or 0.4 , and the approximate range of $\mathrm{Re}_{\mathrm{D}}$ covered in this test is highlighted in figure 13.

As expected, the secondary suction peaks at $\theta \approx 140^{\circ}$ and $210^{\circ}$ due to the forebody vortices are most prevalent at the lowest and the highest Reynolds numbers. There are only small differences between the higher Reynolds number data $\left(R_{C} \geq 1.9\right.$ million) in figure 12b. The lowest Reynolds number data $\left(R_{C}=0.7\right.$ million) was fundamentally different at $\alpha \approx 66^{\circ}$. The pressure distribution for this Reynolds number resembles more of a laminar flow field since there is little pressure recovery before separation (iccurs at $\theta \approx 90^{\circ}$ and $270^{\circ}$. The higher Reynolds number data in this figure exhibit a transitional houndary layer characterized by the presence of a separation bubble at $\theta \approx 100^{\circ}$ and $260^{\circ}$.

$A$ distinct difference in the forebody flow is noted when comparing the lowest Reynolds number pressure distributions $\left(R_{C} \approx 0.7\right.$ million or $\operatorname{Re}_{\mathrm{f}} \approx 0.28$ million) for $\alpha \approx 45^{\circ}$ and $66^{\circ}$. At $\alpha \approx 45^{\circ}$ the forebody flow exhibits more of a transitional boundary layer (haracter while the data at $\alpha \approx 66^{\circ}$ indicate a more laminar boundary layer state. This demonstrates the lower critical Reynolds number boundary (between the $L$ and $T$ flow regimes) variation with angle of attack shown in figure 13.

These Reynolds number effects can also be detected in the normal $\left(C_{N}\right)$ and side $\left(C_{Y}\right)$ force data. Figures 14 and 15 show the $C_{N}$ and $C_{Y}$ data for the same test conditions as figures $12 \mathrm{a}$ and $12 \mathrm{~b}$, respectively. The moderate angle-of-attack data shown in figure 14 does not indicate a significant Reynolds number effect on $C_{N}$ or $C_{Y}$. All the pressure data for $\alpha=45^{\circ}$ ixhibit a transitional to fully turbulent boundary layer state, and as expected the variations in $C_{N}$ and $C_{Y}$ with $R_{C}$ are minimal. ${ }^{8.12}$ The higher angle of attack data shown in figure 15 reveal more variation $C_{N}$ and $C_{Y}$ for the $R_{C} \approx 0.7$ million condition. This higher force data was expected since the pressure distribution for $\alpha \approx 66^{\circ}$ had a more laminar boundary layer characteristic. ${ }^{10}$

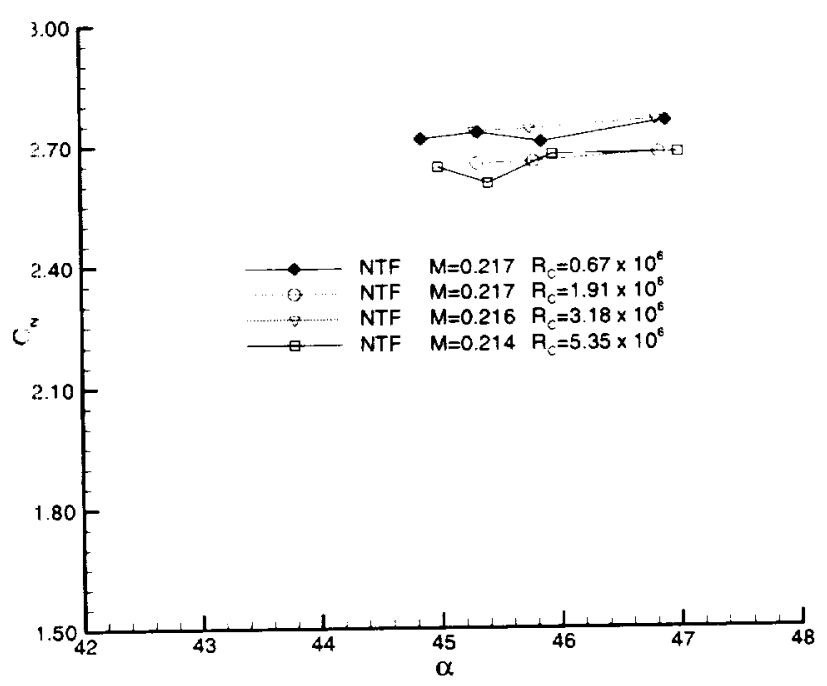

14a) Normal Force $\left(\mathrm{C}_{\mathrm{N}}\right)$ Variation

Figure 14: Reynolds Number Effects on $C_{N}$ and $C_{Y}$ for $\alpha \approx 45^{\circ}$ 


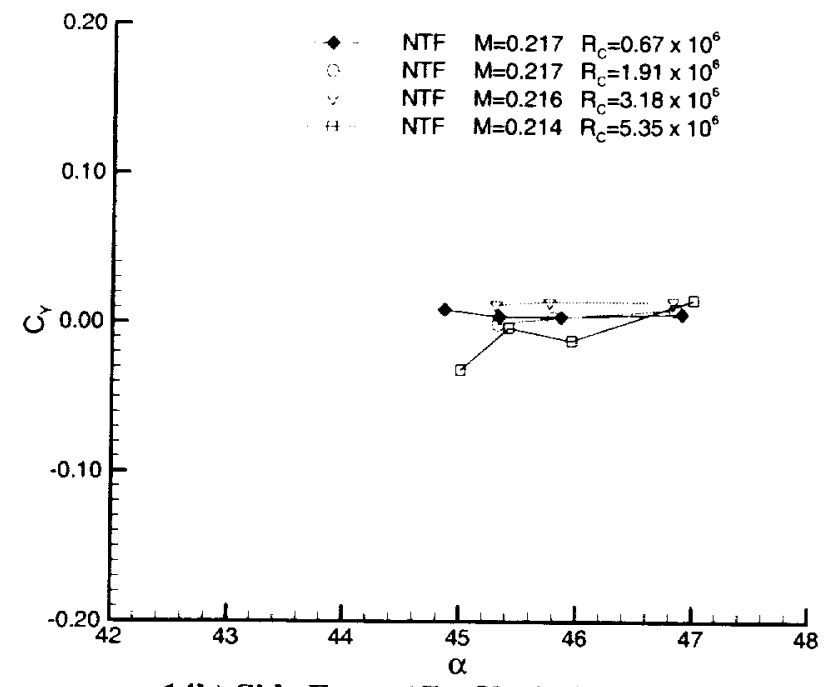

14b) Side Force $\left(C_{Y}\right)$ Variation

Figure 14: Concluded

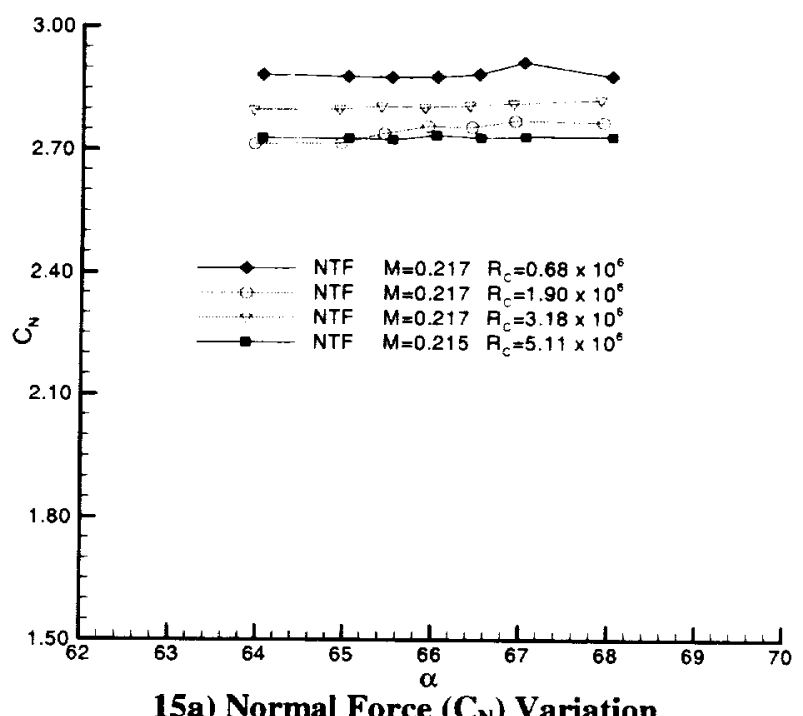

Figure 15: Reynolds Number Effects on $C_{N}$ and $C_{Y}$ for $\alpha \approx 66^{\circ}$

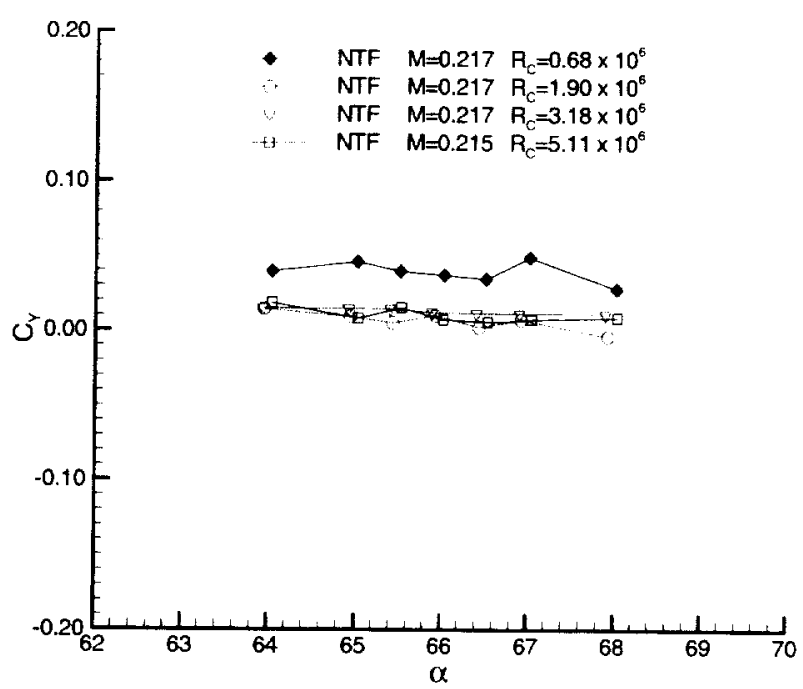

15b) Side Force $\left(C_{Y}\right)$ Variation

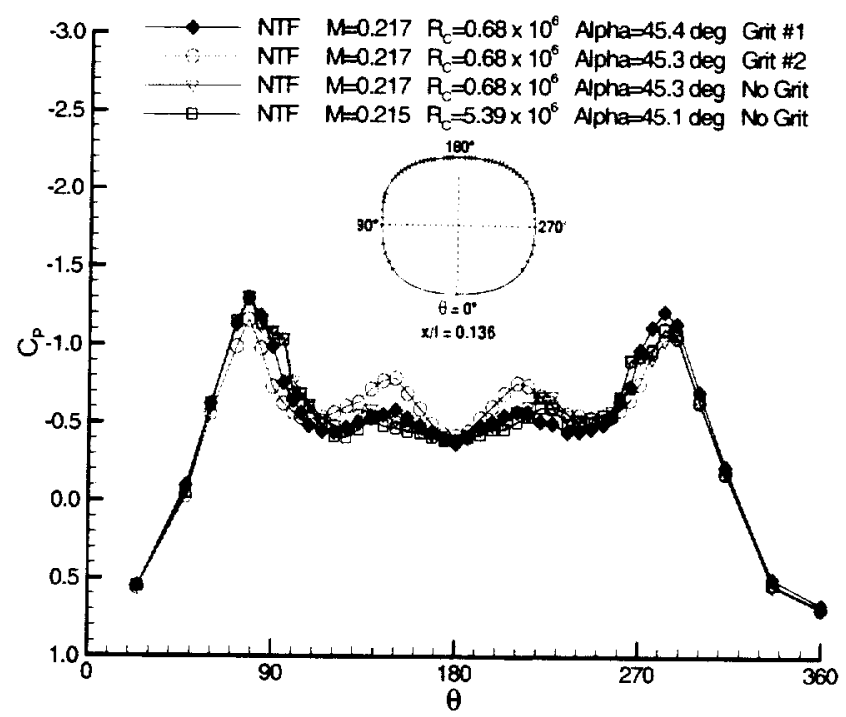

Figure 16: Effect of Transition on Forebody Pressures at $\alpha=45^{\circ}$

Effect of Transition on the Forebody

The effect of two different fixed transition patterns on the NTF model forebody was also studied during this test program. The purpose of this study was to determine if better tunnel to flight correlation could be attained through the use of fixed transition. Twin grit strips were applied starting at the end of the nose strakes and extending approximately 7 inches to $x / 1 \approx 0.23$. Transition pattern $\# 1$ was a band of $\# 80$ carborundum grit that had a constant width of approximately 0.25 inches. Transition pattern $\# 2$ was also a band of $\# 80$ carborundum grit that varied in width from 0.25 inches wide at the nose strake to approximately 1.0 inch wide at $x / l \approx 0.23$. Figure 16 shows forebody pressure distributions for both transition patterns for $M \approx 0.22, R_{C} \approx 0.7$ million, and 
$\alpha \approx 45^{\circ}$. For reference, transition free data at both the low and high Reynolds number conditions is also included in this figure. Note that at this angle of attack the low and high Reynolds number free transition data match reasonably well without any forced transition. The data obtained from transition pattern \# 1 resemble a fully turbulent pressure distribution. The vortices due to the forebody are more prominent for transition pattern \#2. Both transition patterns are reasonably symmetric analogous to the NTF flight Reynolds number data at this angle of attack. However, transition pattern \# I appears to more closely simulate the high Reynolds number condition.

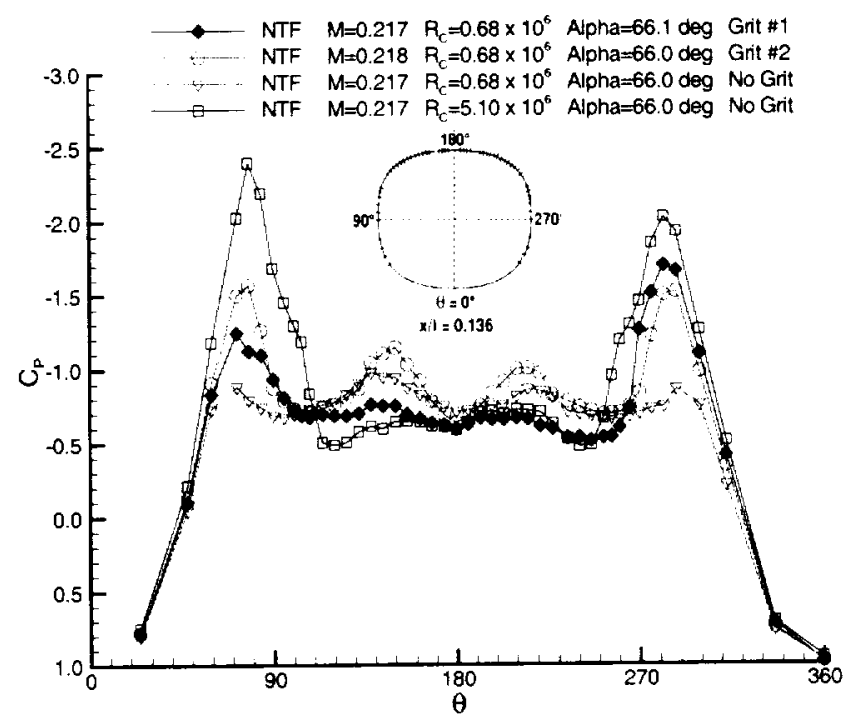

Figure 17: Effect of Transition on Forebody Pressures at $\alpha \approx 66^{\circ}$

Figure 17 shows forebody pressure distributions for both transition patterns for $M \approx 0.22, R_{C} \approx 0.7$ million, and $\alpha \approx 66^{\circ}$. Again, transition pattern $\# 1$ resembles a fully turbulent pressure distribution, and the effect of the forebody vortices is most prominent for transition pattern \#2. Both transition patterns eliminate the laminar flow field observed in the low Reynolds number transition free pressure distribution at this angle-of-attack. The high suction peaks at $\theta \approx 70^{\circ}$ and $290^{\circ}$ for the NTF flight Reynolds number data are not matched by either of the fixed transition patterns, although slight asymmetries are observed in both transition pattern pressure distributions analogous to the flight Reynolds number data. Fixed transition data were only obtained at the lowest Reynolds number condition, $R_{C} \approx 0.7$ million, during this test program.

Since the time of this test additional research has been performed providing additional insight into gritting strategies for high angle-of-attack investigations. ${ }^{13}$ Twin grit strips on the model forebody are still preferred, but the width of these strips is now recommended to be approximately 0.13 inches. A constant width grit pattern is recommended. It would be interesting to test this new transition pattern on the $1 / 16^{\text {th }}$ scale $X-29$ model at flight Reynolds number, $R_{C} \approx 5$ million, for angles of attack greater than $50^{\circ}$ to see if an asymmetric forebody flow field develops similar to those observed in the X-29A flight data. It would also be interesting to test this new transition pattern at all test Reynolds numbers, not just flight. to determine if the new pattern actually makes the low Reynolds numbers better resemble the flight pressure distributions.

\section{Conclusion}

Results from the NTF X-29 High Alpha test have been presented. The NTF high Reynolds number forebody pressure data and the $\mathrm{X}-29 \mathrm{~A}$ flight test data showed good correlation up to $\alpha=50^{\circ}$. For angles of attack above $50^{\circ}$, the flight pressure distributions become asymmetric and do not correlate as well with the high Reynolds number NTF data. The differences in the pressure distributions were attributed to a difference in the boundary layer states between the NTF model and the X-29A research airplane. The difference in the boundary layer states is most likely caused by a difference in the surface roughness between the two test articles, and the external equipment on the X-29A research airplane forebody and nose boom that was not modeled on the $1 / 16^{\text {th }}$ scale NTF model. The wall interference associated with using knuckle position \#3 on the NTF $\mathrm{X}-29$ high alpha sting may also contribute to the discrepancies between the tunnel to flight pressure distributions for angles of attack above $50^{\circ}$. The Reynolds number effects on the NTF model forebody pressures for moderate and high angles of attack were also presented. The lowest Reynolds number data ( $R_{C} \approx 0.7$ million) at $\alpha=66^{\circ}$ showed a laminar flow field which was substantially different from the higher Reynolds number ( $R_{C} \geq 1.9$ million) pressure distributions that exhibited more of a transitional boundary layer characteristic. Fixing transition on the NTF model forebody for the lowest test Reynolds number condition improved the correlation to the higher NTF Reynolds number data, but still showed some fundamental differences with flight Reynolds number pressure distribution. 


\section{$\underline{\text { References }}$}

1) Moore, M., Frei. D., X-29 Forward Swept Wing Aerodynamic Overview, AIAA-831834, July 1983.

2) Fisher, D., Cobleigh, B., Banks, D., Hall, R., and Wahls, R., Reynolds Number Effects at High Angles of Attack, NASA TP-1998206553, June 1998.

3) Luckring, J.M., An Ovenview of National Transonic Facility Investigations for High Performance Military Aerodynamics, AIAA-2001-0906, January 2001.

4) Fisher, D., Richwine, D., Landers, S., Correlation of Forebody Pressures and Aircraft Yawing Moments on the X-29A Aircraft at High Angles of Attack, NASA TM-4417, November 1992.

5) Fuller, D., Guide for Users of the National Transonic Facility, NASA TM-83124, 1981.
Moskovitz, C., Hall, R., DeJarnette, F., Combined Effects of Nose Bluntness and Surface Perturbations on Asymmetric Flow' Past Slender Bodies, Journal of Aircraft, Vol. 27, Number 10, October 1990.

12) Lamont, P.J., The Effect of Reynolds Number on Normal and Side Forces on Ogive Cylinders at High Incidence, AIAA85-1799, August 1985.

13) Hall, R., Erickson, G., Fox, C., Banks, D., Fisher, D., Evaluation of Gritting Strategies for High Angle of Attack Using Wind Tunnel and Flight Test Data for the F/A-18, NASA TP-1998-207670, May 1998.

6) Foster, J., and Adcock, J., User's Guide for the National Transonic Facility Research Data System, NASA TM-110242, April 1996.

7) Lamont, P.J., Pressures Around an Inclined Ogive Cylinder with Laminar, Transitional, and Turbulent Separation, AIAA-80-1556R, March 1982.

8) Polhamus, E., A Review of Some Reynolds Number Effects Related to Bodies at High Angles of Attack, NASA CR-3809, August 1984.

9) Roos, F.W., and Kegelman, J.T., Aerodynamic Characteristics of Three Generic Forebodies at High Angles of Attack, AIAA-91-0275, January 1991.

10) Owens, L., Hemsch, M., Popernack, T., Reynolds Number Effects on Advanced Slender Forebodies for Angles of Attack up to $27^{\circ}$ at Mach 0.2, NASA TP-3493, August 1994. 